\title{
TRAS LA HUELLA DEL SÍLICE PAMPINO. NUEVAS METODOLOGÍAS PARA EL RASTREO DE LAS ÁREAS FUENTE DE APROVISIONAMIENTO LÍTICO EN TALTAL
}

\section{BEHIND THE PATH OF THE PAMPEAN SILEX. NEW METHODOLOGIES TO TRACE TALTAL'S LITHIC SOURCE AREAS}

\author{
César Borie 1 , Ximena Power ${ }^{2}$, Sonia Parra ${ }^{3}$, Hernán Salinas ${ }^{4}$, Pierre Rostan5, Patricio Galarce ${ }^{6}$, \\ Inguer Peña ${ }^{7}$ y Francesca Traverso ${ }^{8}$
}

\begin{abstract}
Resumen
Las materias primas silíceas desempeñaron un rol fundamental en la organización tecnológica de las poblaciones arcaicas de Taltal, tal como atestigua su ubicuidad en los sitios arqueológicos locales. Sin embargo, aspectos cruciales como sus fuentes de origen y las estrategias desplegadas para su obtención han sido referidas solo tangencialmente en la literatura arqueológica de la zona. Este trabajo desarrolla una sistematización de la información arqueológica disponible para el área de estudio y una propuesta metodológica dirigida al rastreo remoto de las potenciales áreas fuente de aprovisionamiento lítico arcaico. Adicionalmente, se presentan los primeros resultados de las labores de reconocimiento en la Depresión Interme-

dia de Taltal y del análisis de imágenes satelitales multiespectrales.

Palabras claves: Arcaico - teledetección satelital - espectroscopía de reflectividad - Depresión Intermedia - costa arreica - norte de Chile.
\end{abstract}

\begin{abstract}
Siliceous raw materials played a key role in the technological organization of Taltal's archaic populations, as witnessed by its ubiquity in the local archaeological sites. Nevertheless, crucial aspects like their sources and the strategies deployed for their procurement have been referred only tangentially in the archaeological literature of the area. This work develops a systematization of the archaeological data available for the study area and a methodological proposal for the remote tracking of potential archaic quarries. Additionally, the first results of field surveying in Taltal's Intermediate Depression and the analysis of multispectral satellite imagery is presented.

Keywords: Archaic Period - satellite remote sensing - reflectance spectroscopy - Intermediate Depression - arid coast - northern Chile.
\end{abstract}

Recibido: marzo 2016. Aceptado: diciembre 2016.

\section{$*$ Introducción}

Las materias primas líticas, debido a su excelente conservación, potencial informativo y significación para las poblaciones cazadoras-recolectoras, han constituido una entrada clave para el estudio arqueológico de sus patrones de asentamiento, subsistencia y movilidad (Andrefsky 2008; Binford 1979, 1980; Gould y Saggers 1985; Chatters 1987; Kelly 1988, 2012; Pigniolo 2009; Wilson 2007, entre otros).

Las diversas estrategias de aprovisionamiento de material lítico documentadas arqueológica y etnográficamente entre grupos cazadores-recolectores, han sido abordadas en su relación con las condiciones sociales y ambientales en que se desenvolvieron estas comunidades a lo largo de su extensa trayectoria histórica. En consecuencia, la estructura de recursos ofrecida por el entorno, específicamente en términos del paisaje lítico, y las características particulares de los materiales líticos requeridos para satisfacer distintas necesidades se destacan como fructíferas vías de acceso a la organización tecnológica de los grupos cazadores-recolectores prehispánicos (Goodyear 1979; Gould y Saggers 1985; Bamforth 1986; Nelson 1991; Andrefsky 1994; Wilson 2007; McCall 2012, entre otros).

1 Programa de Doctorado en Antropología UCN-UTA, Universidad Católica del Norte, Gustavo Le Paige 380, San Pedro de Atacama, CHILE. Email: cbco32@alumnos.ucn.cl

2 Programa de Doctorado en Antropología UCN-UTA, Universidad Católica del Norte, Gustavo Le Paige 380, San Pedro de Atacama, CHILE. Email: anneke.xp@gmail.com

3 Departamento de Antropología, Facultad de Ciencias Sociales, Universidad de Chile. Ignacio Carrera Pinto 1045, piso 2, Ñuñoa, Santiago, CHILE. Email: soniparrao@gmail.com

4 Departamento de Antropología, Facultad de Ciencias Sociales, Universidad de Chile. Ignacio Carrera Pinto 1045, piso 2, Ñuñoa, Santiago, CHILE. Email: salinas.williams@gmail.com

5 Bureau d'Étude Mines \& Avenir, 05380 Châteauroux Les Alpes, FRANCIA. Email: roc2@wanadoo.fr

6 Archeos Chile Consultores en Arqueología Ltda. El Tilo 1152, La Florida, Santiago, CHILE. Email: patogalarce@yahoo.es

7 Departamento de Antropología, Facultad de Ciencias Sociales, Universidad de Chile. Ignacio Carrera Pinto 1045, piso 2, Nuñoa, Santiago, CHILE.Email: inguer.pena@ug.uchile.cl

8 Departamento de Antropología, Facultad de Ciencias Sociales, Universidad de Chile. Ignacio Carrera Pinto 1045, piso 2, Nuñoa, Santiago, CHILE.Email: fran.traverso@gmail.com 
La zona de Taltal se posiciona como un laboratorio natural, cuya situación geográfica y proceso histórico particular invitan a indagar en la logística implicada en las modalidades de acceso directo a recursos líticos de alta calidad por parte de las poblaciones cazadoras-recolectoras-pescadoras locales. Esto como consecuencia de la antigüedad e intensidad de sus ocupaciones costeras (Andrade y Salazar 2011; Capdeville 1921; Castelleti 2007; Contreras et al. 2011; Salazar et al. 2013; Salazar et al. 2015), la ausencia de asentamientos estables en los vastos territorios que se abren al este de su productivo litoral y su relativamente tardía conexión con comunidades agropastoriles de oasis y valles interiores (Bittmann 1977; Bittmann y Munizaga 1984; Núñez 1984; Salazar et al. 2015).

Desde principios del siglo XX, distintos investigadores han señalado la Depresión Intermedia hiperárida como la posible área de origen de las rocas silíceas y silicificadas registradas en abundancia, como piezas formatizadas o lascas, en los contextos litorales de Taltal, postulando que estas materias primas serían trabajadas en sus lugares de procedencia antes de ser trasladadas a los sitios residenciales y logísticos de la costa (Bird 1943, 1965; Le Paige 1964; Núñez 1984; Uhle 1916; Urrejola y Orellana 2000; Castelleti 2007; Castelleti et al. 2010; Galarce y Santander 2013).

Recientes estudios en sitios arqueológicos de la costa de Taltal han confirmado el uso extensivo de este tipo de rocas de alta calidad para la talla y su rol fundamental como soporte tecnológico de los grupos cazadores-recolectores (Salinas et al. 2014; Galarce y Santander 2013). En tanto, el desierto absoluto que se extiende al este de la cordillera de la Costa, ha aportado hallazgos de talleres líticos, eventos de talla, rutas de desplazamiento pedestre y estructuras en forma de herradura. Estos registros han sido interpretados como evidencias de estrategias especializadas de movilidad logística, articuladas desde los asentamientos base costeros para acceder a un sistema de depósitos silícicos que se extendería a lo largo de la Depresión Intermedia desde el sur de Iquique hasta Chañaral (Blanco et al. 2010; Pimentel et al. 2011).

La disposición de las fuentes primarias de rocas silíceas y silicificadas como depósitos localizados en estos ambientes hiperáridos, con baja disturbación y superficialmente expuestos, se enmarca en un entorno estable y con una baja tasa de erosión (Placzek et al. 2010), el cual no ha sido a la fecha objeto de estudios arqueológicos dentro de programas de investigación sistemáticos.

En este estudio se exploran distintas estrategias metodológicas para localizar las potenciales fuentes de materias primas líticas de alta calidad para la talla explotadas por los cazadores-recolectores-pescadores prehispánicos de Taltal. La reconstrucción del paisaje lítico local (sensu Gould y Saggers 1985) se considera un paso clave para comprender la organización tecnológica requerida para la integración de dichos recursos abióticos del desierto absoluto dentro del vasto territorio de las poblaciones costeras.

Se busca, en última instancia, sentar las bases para el estudio en profundidad de las estrategias de aprovisionamiento de este tipo de materias primas líticas por parte de las poblaciones del litoral meridional de la región de Antofagasta, antecedentes que permitirán ampliar el conocimiento acerca de los patrones de asentamiento y movilidad articulados desde los asentamientos litorales durante el Período Arcaico (ca. 12.000 - 1.500 cal. AP) (Salazar et al. 2015).

Se presentan a continuación los primeros resultados de los trabajos orientados a la identificación de fuentes de rocas silíceas utilizadas ampliamente por las sociedades costeras arcaicas del área de Taltal (Castelleti 2007; Galarce y Santander 2013; Salinas et al. 2014; Salazar et al. 2015). Estos resultados se organizan a partir de tres objetivos principales: 1) sistematizar los antecedentes disponibles a la fecha acerca de hallazgos de sitios de procesamiento lítico en la Depresión Intermedia de Taltal; 2) proponer una metodología para el rastreo remoto y estudio de las principales fuentes de materias primas silíceas en el área; y 3) presentar resultados preliminares de una estrategia de teledetección satelital de fuentes líticas en desarrollo y nuevos datos fruto de reconocimientos focalizados en terreno. De esta forma se espera aportar un panorama inicial acerca del aprovisionamiento de materias primas silíceas por parte de las poblaciones arcaicas costeras del desierto de Atacama y contribuir a la discusión y desarrollo de nuevas metodologías para la identificación y caracterización de áreas fuente en contextos de estudio afines. 


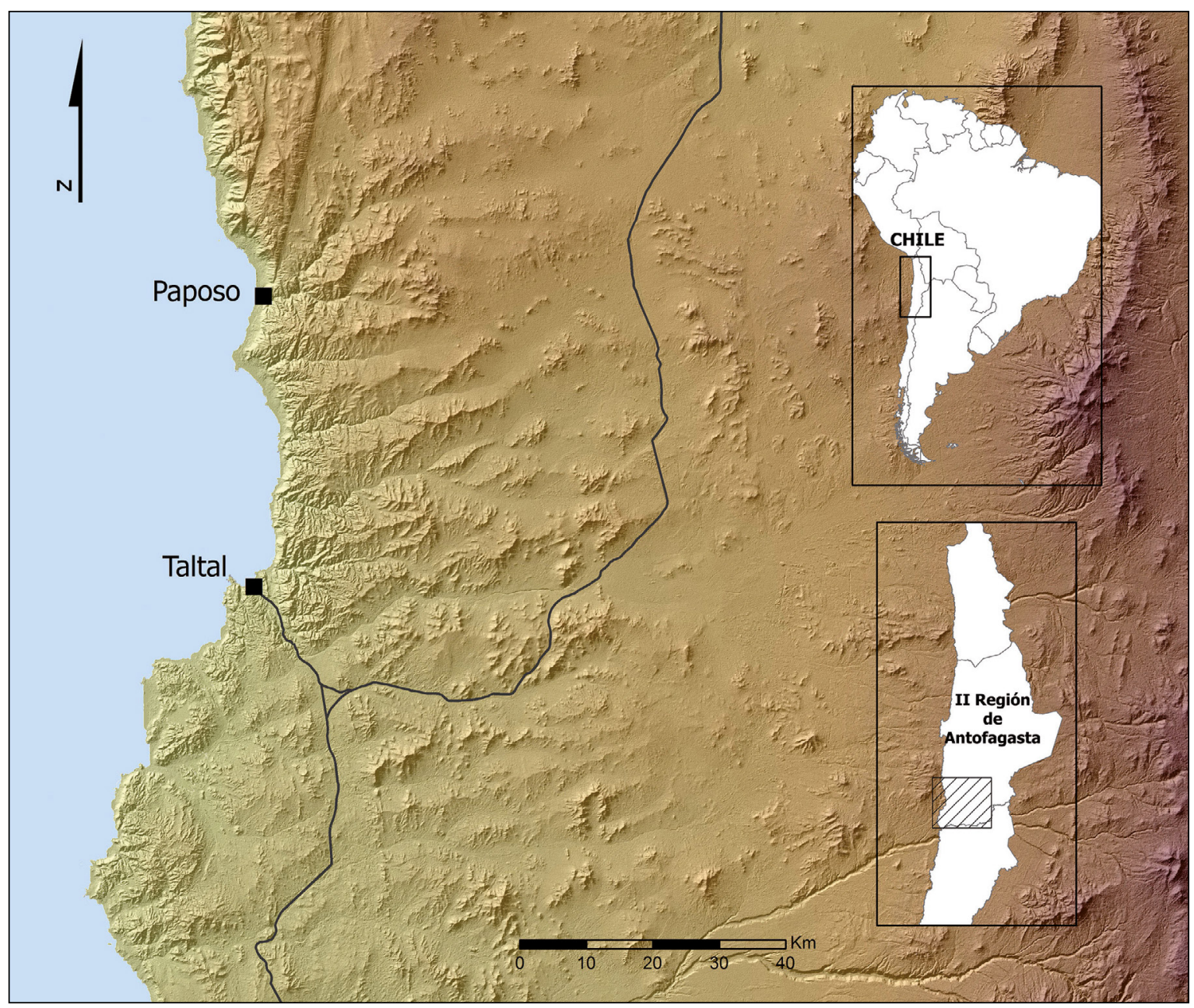

Figura 1. Ubicación y vista general del área de estudio.

\section{$*$ Contexto ambiental}

El área de estudio comprendida por esta investigación $\left(24-27^{\circ} \mathrm{S}\right)$ constituye el segmento más meridional del litoral arreico del norte de Chile y se define por condiciones extremas y contrastantes (Figura 1).

En una revisión en sentido latitudinal, la primera unidad fisiográfica corresponde a la Plataforma Litoral, espacio constituido por un ecosistema marino de alta riqueza y productividad (Ortlieb et al. 2011), enfrentado a una estrecha y abrupta franja costera sin cursos de agua estables. Los recursos hídricos se encuentran restringidos a pequeñas aguadas localizadas en la terraza litoral y en la cordillera de la Costa (Núñez y Varela 1967-68). Estos acuíferos, tras el predominio de condiciones hiperáridas desde fines del Pleistoceno, habrían sido recargados prin- cipalmente gracias a la influencia de condiciones húmedas ligadas a la acción más regular de El Niño-Oscilación del Sur (ENOS), entre el 5000 y 3000 AP (Herrera y Custodio 2014).

Un régimen de precipitaciones cuyo promedio no supera los $8 \mathrm{~mm}$ anuales (Quezada et al. 2010) restringe el desarrollo de comunidades vegetales de cactáceas, herbáceas y arbustos bajos a sectores circundantes a las aguadas y a aquellos espacios del farellón costero más expuestos a las neblinas de advección o camanchacas (Pliscoff y Luebert 2008). Estos parches acotados de recursos, a su vez, concentran la mayor diversidad y abundancia de fauna vertebrada e invertebrada (Marquet et al. 1998).

La cordillera de la Costa, por su parte, abrupta y con alturas que promedian los 2 mil msnm (Guendon 2008), 
bloquea la influencia de las camanchacas, definiendo condiciones hiperáridas en los terrenos que se extienden hacia el este. Allí se despliega la Depresión Intermedia, una planicie desértica, o pampa, conformada por una amplia depresión longitudinal interrumpida por serranías con altitudes de 2.500 a $3.000 \mathrm{msnm}$ y cursos de agua intermitentes que se encajonan al aproximarse a la costa. Estas quebradas de orientación predominante este-oeste, son activadas solo ocasionalmente, al menos desde el Holoceno Medio, por las lluvias torrenciales asociadas al ENOS (Vargas et al. 2006).

Las prácticamente nulas precipitaciones, fuerte oscilación térmica diaria y la ausencia casi absoluta de fuentes de agua superficiales y, por ende, de recursos bióticos en la Depresión Intermedia (Houston 2006), contrastan con su riqueza en minerales y rocas (IGM 1990). Estos rasgos definen la pampa como un paisaje lítico que se destaca por su bajísima tasa de erosión, pero cuyas superficies depositacionales se habrían visto afectadas por episodios de lluvia y arrastre de material esporádicos de alta magnitud entre el Mioceno Temprano y el Pleistoceno (Dunai et al. 2005; Placzek et al. 2010).

\section{$\diamond$ Antecedentes}

Las evidencias de asentamientos de poblaciones prehispánicas en el borde costero, expresadas en los imponentes y densos conchales de la localidad de Taltal, han sido objeto de atención por parte de investigadores nacionales y extranjeros desde principios del siglo XX (Uhle 1916; Capdeville 1921; Bird 1943, 1965; Berdichewsky 1962; Silva y Bahamondes 1969, Durán 1981; Gaete et al. 2003; Castelleti 2007; Castelleti et al. 2010; Llagostera y Llagostera 2010; Andrade y Salazar 2011; Contreras et al. 2011; Olguín et al. 2014; Power 2015; Salazar et al. 2015, entre otros).

Estudios recientes han profundizado en las particularidades de la larga y potente historia ocupacional prehispánica de Taltal, abordando de manera integrada aspectos como la tecnología, el patrón de asentamiento y la subsistencia de los grupos cazadores-recolectores-pescadores locales en nuevas síntesis interpretativas que se traducen en secuencias cronológicas procesuales de referencia para la zona (Castelleti 2007; Salazar et al. 2015).
Abarcando desde la transición Pleistoceno-Holoceno (12.000 cal. AP) hasta los inicios de la era cristiana, la secuencia arcaica de Taltal (Salazar et al. 2015) se destaca fundamentalmente por tres aspectos que son relevantes para la problemática en estudio. Por un lado, la persistencia de un patrón de asentamiento en la franja costera vinculado estrechamente a aguadas y puntillas rocosas (Núñez y Varela 1967-1968; Castelleti 2007; Borie y Soto 2011), donde se desarrollan ocupaciones residenciales de carácter semipermanente (Núñez 1984; Castelleti 2007; Andrade y Salazar 2011; Salazar et al. 2015). Por otro, una temprana adaptación marítima, consolidada hacia los 7000 años cal AP y sostenida durante todo el Arcaico. ${ }^{9}$ Esta fuerte orientación marítima se manifiesta en un kit artefactual especializado hacia labores de caza, pesca y recolección costera, y en un énfasis en el consumo de recursos marinos, los que cubren una amplia gama de peces, moluscos y mamíferos (Castelleti 2007; Olguín et al. 2014; Rebolledo 2014; Andrade et al. 2015; Power 2015; Salazar et al. 2015). Finalmente, su condición de relativo aislamiento hasta etapas tardías de la prehistoria, con una marginal incorporación de bienes de culturas agropastoriles de valles y oasis interiores (como cerámica y metales) desde el 3000 cal AP (Núñez 1984; Salazar et al. 2015; Varela 2009). Recién a partir del Período Intermedio Tardío los contactos con este tipo de desarrollos se volverían más estables ${ }^{10}$ (Núñez 1984; Salazar et al. 2015).

Estos aspectos al ser considerados en el marco de las particulares condiciones ambientales del extremo meridional de la costa arreica, permiten comprender de mejor manera la persistencia de un modo de vida arcaico en la zona (Bird 1943; Bittmann y Munizaga 1984; Núñez 1984; Castelleti 2007; Salazar et al. 2015), cualidad que, como veremos a continuación, se extiende de manera no-

\footnotetext{
9 Se considera incluido aquí el Período Formativo (3000 - 1500 AP) de la secuencia de Castelleti (2007). Para más detalles consultar Salazar et al. 2015.

10 Sin embargo, es preciso señalar que estas comunidades costeras habrían participado, al menos desde el $6000 \mathrm{AP}$, en procesos de complejización social que involucraron transformaciones tecnológicas, contactos interétnicos e intercambio a larga distancia, expandiendo sus influencias en una extensa zona litoral que comprometió el Norte Grande y Semiárido chileno, e incluyó, a su vez, relaciones con desarrollos agropastoriles del interior de Atacama (Berdichewsky 1962; Mena 1984; Núñez 1984; Castelleti 2007; Gallardo 2009; Ballester y Gallardo 2011; Contreras et al. 2011; Olguín et al. 2014; Salazar et al. 2015, entre otros).
} 
table a la organización de la tecnología lítica de sus antiguos pobladores.

Tal como atestiguan los conjuntos líticos de las primeras ocupaciones de la costa Taltal, tempranamente se habría consolidado en la zona una estrategia tecnológica sustentada en la utilización extensiva de materias primas silíceas y silicificadas de alta calidad para la talla, las que serían abundantes y accesibles en la pampa al oriente de la cordillera de la Costa (Castelleti 2007; Galarce y Santander 2013).

Este énfasis en el empleo de materias primas de alta calidad y la baja frecuencia de rocas de grano medio y grueso (andesitas y basalto) en los contextos habitacionales (Bird 1965; Castelleti 2007; Galarce y Santander 2013; Salinas et al. 2014), será una constante en los contextos costeros de Taltal, situación que ha llevado a proponer la relevancia de las rocas silíceas como soporte tecnológico de los grupos de cazadores-recolectores arcaicos locales (Galarce y Santander 2013; Salinas et al. 2014).

El manejo diferencial de las materias primas líticas por parte de las poblaciones arcaicas de Taltal ha sido interpretado como parte de estrategias de organización tecnológica que en el caso de los campamentos residenciales se definen como "expeditivo-conservadas", basándose en el manejo conservado del sílice y en el aprovechamiento expeditivo de rocas no silíceas (Castelleti 2007; Power 2015). Por su parte, los campamentos de tareas se caracterizarán por estrategias tecnológicas planificadas, manifiestas en el uso prácticamente exclusivo de preformas y derivados silíceos (Castelleti 2007).

Dado que la disponibilidad de las rocas silíceas requeridas para sustentar estas estrategias ha sido generalmente adscrita a fuentes localizadas en la Depresión Intermedia (Bird 1943, 1965; Le Paige 1964; Núñez 1984; Uhle 1916; Urrejola y Orellana 2000; Castelleti 2007; Castelleti et al. 2010; Galarce y Santander 2013), su procuramiento directo habría precisado el establecimiento de circuitos de movilidad organizados desde la costa, implicando incursiones especializadas y planificadas a la pampa (Castelleti 2007; Salazar et al. 2013). Estos rasgos darían cuenta de un acabado conocimiento del paisaje lítico local (Galarce y Santander 2013; Salazar et al. 2013, 2015).
La presencia de talleres líticos y canteras de sílice en la Depresión Intermedia de Taltal fue inicialmente reportada por Uhle (1916), quien los localiza en asociación a estructuras en forma de herradura en el centro de esta formación, a unos $2.000 \mathrm{msnm}$ (Uhle 1916). Espacios interiores que serán también señalados por Bird (1943, 1965) y Le Paige (1964) como la posible área de procedencia de las rocas silíceas registradas en abundancia en los asentamientos costeros precerámicos de Taltal (Bird 1943). Este tipo de rocas serían trabajadas inicialmente en la pampa antes de transportarlas a los sitios costeros donde se concretaría su proceso de manufactura (Le Paige 1964; Bird 1965).

Posteriormente, Lautaro Núñez (1984) retomará estos datos, sumando a ellos los hallazgos que realizara junto a Guillermo Chong (Chong y Núñez Ms, citado en Núñez 1984) en terrenos próximos al trazado de la carretera Panamericana entre Taltal y Antofagasta. En dicho trabajo, se describen hallazgos de dispersiones líticas asociadas a estructuras en "herradura" que define como "talleresparaderos" (Núñez 1984), donde el registro en superficie de conchas, restos de peces, percutores de rodados marinos, además de manos y yunques con pigmento rojo, es interpretado como el producto de estadías temporales de grupos costeros, orientadas a la obtención de rocas silíceas de alta calidad para la talla controlada y de minerales en un ámbito carente de recursos de subsistencia (Núñez 1984).

Por su parte, Urrejola y Orellana (2000), luego de investigar el patrón de distribución de materias primas en los territorios desérticos al interior de Taltal, las etapas de reducción lítica representadas en estructuras de pernocte y sus depósitos estratigráficos, concluirán que se trata de evidencias de ocupaciones múltiples y breves, fruto de estrategias logísticas de aprovisionamiento articuladas desde los asentamientos costeros que incluían sitios focalizados exclusivamente en la obtención de recursos líticos, otros empleados para la captación de esta materia prima y como campamento, y finalmente sitios utilizados solo como campamento (Urrejola y Orellana 2000).

Desde esta misma perspectiva han sido comprendidas las concentraciones líticas registradas en el marco de diversos estudios de impacto ambiental desarrollados en la Depresión Intermedia de Taltal (Contreras 2006; Ajata 2013; SGA 2013a y 2013b; IAL 2014, entre otros). Estos 
estudios, que comprometen terrenos ubicados entre el borde oriental de la cordillera de la Costa y las estribaciones hacia el poniente de la cordillera de Domeyko, coinciden en señalar la presencia predominante de sitios de procesamiento lítico de distinta envergadura. Entre ellos se registran eventos de talla discretos, como también, grandes extensiones de restos líticos con o sin asociación a estructuras subcirculares tipo paraviento o acumulaciones irregulares de piedras. ${ }^{11}$ Cabe destacar que en superficie estos contextos presentan de forma exclusiva, o marcadamente preponderante, derivados del desbaste inicial de materias primas silíceas (descritas como sílice, calcedonia, jaspe, cuarzo y cuarcita) a los que se suman recurrentemente grandes preformas o matrices bifaciales elaboradas en este tipo de rocas (Ajata 2013; IAL 2014).

El énfasis de los sitios de la pampa desértica en el procesamiento primario de materias primas silíceas y la producción de matrices bifaciales corresponde a un hecho tempranamente observado por Le Paige (1964) en los densos talleres líticos de Pampa Altamira (Le Paige 1964), que será constatado por el equipo de Urrejola y Orellana (2000) y por los estudios de Lino Contreras (Contreras 2006) en ese mismo sector, distante más de $80 \mathrm{~km}$ de la costa.

Dentro de este contexto, la producción de matrices bifaciales es entendida como una respuesta tecnológica de grupos cazadores-recolectores móviles adecuada a las restricciones impuestas por el medio (Kelly 1988) y, en nuestro caso específico, dirigida a obtener, reducir y transportar el recurso lítico a las locaciones costeras donde se produciría su transformación y uso final (Blanco et al. 2010; Urrejola y Orellana 2000; Galarce y Santander 2013). Estos rasgos son coherentes con el predominio en los conjuntos líticos arcaicos de sitios residenciales y de tarea en la costa de Taltal de indicadores de reducción y adelgazamiento bifacial de matrices que deriva en artefactos formatizados o lascas (Galarce y Santander 2013).

Esta estrategia ha sido formalizada, a partir de pesquisas bibliográficas y de las evidencias arqueológicas de la

11 Cabe precisar que son numerosos también los hallazgos de sendas o senderos pedestres simples, que en algunos casos específicos representan la categoría de sitio más abundante junto a otros rasgos lineales como huellas de carreta (SGA 2013a, 2013b y $2013 \mathrm{c}$ ).
Depresión Intermedia del extremo septentrional de la región de Antofagasta, como un sistema de aprovisionamiento basado en la obtención de matrices bifaciales (Blanco et al. 2010), integrado en una modalidad costera de movilidad de raigambre arcaica (Pimentel et al. 2011). Esta modalidad de circulación pedestre estaría orientada a dar acceso a un sistema de depósitos silícicos que se extendería a lo largo de la Depresión Intermedia desde el sur de Iquique hasta Chañaral, conformando un cordón desplegado entre 40 y $80 \mathrm{~km}$ al interior de la línea de costa actual (Blanco et al. 2010).

Es preciso considerar que, si bien los sitios arqueológicos emplazados en los terrenos desérticos que se extienden al este de la costa arreica manifiestan una tendencia generalizada hacia la obtención y procesamiento de materias primas líticas de alta calidad para la talla, los contextos reportados por Cabello (2008) en el sector de Mina Guanaco, entre 90 y $120 \mathrm{~km}$ al interior de la costa norte de Taltal, darían cuenta de locaciones con una mayor diversidad funcional. Es el caso de dos campamentos prehispánicos a cielo abierto con presencia de restos malacológicos, abundantes desechos de talla lítica e instrumentos formatizados, como puntas de proyectil, cuchillos y raspadores, donde se habrían llevado a cabo labores de caza y destazamiento de presas aprovechando espacios próximos a fuentes de agua que afloran al poniente de la cordillera de Domeyko (Cabello 2008).

Si bien en estos yacimientos se registraron en superficie artefactos diagnósticos del Período Formativo, no es descartable la existencia de ocupaciones de data más antigua. En tanto, el registro de conchas del Pacífico evidencia sus relaciones con el litoral arreico (Cabello 2008), sean ellas producto del establecimiento temporal de contingentes costeros en esta zona de quebradas y vegas precordilleranas, o de dinámicas de intercambio establecidas entre grupos cazadores-recolectores que circularon por estos ambientes interiores y las poblaciones costeras locales. A esta posibilidad de una circulación arcaica circumpuneña parecen aportar los registros de la más meridional localidad arqueológica de Pampa Austral (Peralta et al. 2010).

Los antecedentes aquí presentados esbozan un panorama arqueológico del área de estudio que revela los parajes desérticos de la Depresión Intermedia como un 
territorio donde se desplegaron estrategias tecnológicas especializadas para el aprovisionamiento de materias primas líticas de alta calidad, pero también como un escenario de actividades e interacciones sociales entre cazadores-recolectores cuya amplia movilidad logística les permitió articular eficientemente diversos ambientes y recursos.

\section{* Problema de inVestigación: ORganización TECNOLÓGICA Y PAISAJES LÍTICOS}

En el desierto costero de arré́smo absoluto, la organización de la tecnología lítica de las poblaciones cazadoras-recolectoras-pescadoras arcaicas se definió por estrategias conservadoras y optimizadoras en el manejo de materias primas no-locales ${ }^{12}$ de alta calidad para la talla (Castelleti 2007; Galarce y Santander 2013; Power 2015). Lo anterior, como un recurso que habría enfatizado la disponibilidad de este tipo de rocas durante el desarrollo de un amplio rango de actividades tecnológicas y subsistenciales concentradas en el litoral y la vecina cordillera de la Costa (Castelleti 2007; Castelleti et al. 2010; Galarce y Santander 2013; Salazar et al. 2015).

Estas estrategias conservadoras y optimizadoras relacionadas a la obtención y tratamiento diferencial de recursos líticos extracosteños, se mantendrían en gran medida estables a lo largo de la secuencia cultural prehispánica local a raíz de la continuidad en los requerimientos técnicos impuestos por las dinámicas de asentamiento, movilidad y subsistencia de las poblaciones arcaicas de Taltal. La continuidad de estos requerimientos, una condición vinculada a la posibilidad de anticipar aquellos escenarios de tarea en que la tecnología lítica se encontraba implicada de manera directa o indirecta (McCall 2012), habría repercutido en una sostenida demanda de materias primas de cualidades específicas y de piezas apropiadas para su eficiente manipulación y transporte (Binford 1979; Goodyear 1979; Kelly 1988, 2012; Nelson 1991; Andrefsky 1994).

12 Se entiende por no-local aquellos espacios ubicados por fuera de un radio de $40 \mathrm{~km}$ trazado desde los asentamientos costeros en estudio. Esto siguiendo los datos de distancias máximas aproximadas de traslado de materias primas líticas desde canteras a campamentos habitacionales documentadas etnográficamente (Gould y Saggers 1985; Meltzer 1989).
Tomando en consideración que la selección de materias primas líticas responde principalmente a exigencias funcionales ligadas al uso esperado de los artefactos que con ellas serán elaborados (Greiser y Sheets 1979; McCall 2012), las propiedades físico-mecánicas de las rocas y su distribución espacial en un contexto geográfico determinado se yerguen como factores determinantes (Gould y Saggers 1985; Andrefsky 1994). En vista de ello, explorar las características del paisaje lítico dominado por los cazadores-recolectores-pescadores de Taltal es planteada como una tarea primordial en el marco de esta investigación.

Para abordar la reconstrucción del paisaje lítico arcaico de Taltal, se considera pertinente una aproximación multidisciplinaria que integra técnicas de la arqueología, geología y teledetección, con el propósito de relevar información respecto a la localización de formaciones geológicas potencialmente explotadas como áreas fuente $e^{13}$ en tiempos arcaicos para el aprovisionamiento de materias primas silíceas y silicificadas, e indagar en la estructuración de este paisaje en términos de la movilidad de grupos cazadores-recolectores costeros hacia estas áreas de aprovisionamiento.

Se sostiene que el potencial informativo de la identificación de las fuentes de procedencia de las materias primas de alta calidad registradas en los contextos costeros prehispánicos, pese a su inherente dificultad (Luedtke 1979; Shackley 2008), radica en la relación que se puede establecer entre las distancias de transferencia ${ }^{14} \mathrm{y}$ radios de procuramiento, estrategias de adquisición, interacciones sociales, preferencias tecnológicas y con la localización de rutas específicas de movilidad, aportando datos concretos para estudiar las recurrencias y cambios en los patrones de organización tecnológica, asentamiento y movilidad prehispánicos desde una perspectiva espacial y temporal amplia (Pigniolo 2009; Wilson 2007).

13 El concepto de áreas fuente refiere aquellos terrenos que cubren desde una a múltiples fuentes líticas consideradas afloramientos de una misma formación geológica, incluyendo los depósitos secundarios (aluviales o coluviales) con nódulos desplazados desde estos afloramientos (Browne y Wilson 2013).

14 Distancia que media entre las fuentes de aprovisionamiento de materiales líticos y las locaciones donde se evidencia su procesamiento, uso y descarte (Duke y Steel 2010). 
A continuación se desarrolla una propuesta metodológica para la localización y análisis de áreas fuente de materias primas silíceas y silicificadas utilizadas por grupos cazadores-recolectores arcaicos de Taltal, y el rastreo de las redes de movilidad generadas en torno a ellas. En primer lugar, se especifica la escala de análisis y reseñan las técnicas analíticas implicadas en la presente propuesta, destacando el potencial de su uso integrado y sus ventajas respecto a aproximaciones metodológicas tradicionales. Posteriormente, se detallan las etapas y procedimientos específicos que forman parte de la propuesta metodológica a aplicar para el abordaje de la problemática de investigación.

\section{* ESCAla ESPACIAL Y TEMPORAL DE ANÁLISIS}

El área comprometida por este estudio se localiza en el sector sur de la región de Antofagasta, cubriendo una amplia área geográfica que se extiende desde $80 \mathrm{~km}$ al norte hasta $70 \mathrm{~km}$ al sur de la ciudad de Taltal y se interna en la Depresión Intermedia un promedio de $150 \mathrm{~km}$ lineales desde la línea de costa (Figura 1).

La extensión del área de estudio en sentido norte-sur se define en función de la porción de la franja costera que ha sido sistemáticamente estudiada por los proyectos FONDECYT 1080666, 1110196 y 1151203 . Por ende, cuenta con información comparable derivada de prospecciones y excavaciones sistemáticas, además de varios contextos con fechados absolutos. ${ }^{15}$

En cuanto a su extensión en sentido este-oeste, la fijación de un límite a los $150 \mathrm{~km}$ al este de la línea de costa se considera adecuada para abarcar la diversidad del registro arqueológico de la Depresión Intermedia. Esto comprende un rango espacial que incluye el curso bajo, medio y alto de las principales quebradas longitudinales del área de estudio, además del sector pampino central, espacio distante entre 45 y $90 \mathrm{~km}$ de la costa donde se han registrado numerosos sitios de procesamiento lítico (Contreras 2006; Ajata 2013; SGA 2013a, 2013b y 2013c; IAL 2014) y se conocen al menos dos áreas de afloramiento y cantera de rocas silíceas, una en el sector de Pampa Yolanda Norte, próximo a la oficina Alemania (Salazar et al.

15 La franja sistemáticamente prospectada cubre hasta $20 \mathrm{~km}$ al sur de Taltal. Para los fines de este estudio se extiende a $70 \mathrm{~km}$, incluyendo así la costa frente al sector de Pampa Altamira.
2015) y otro en el sector de Pampa Altamira, destacado en la literatura por la presencia de talleres y canteras de este tipo de materia prima lítica (Contreras 2006; Le Paige 1964, 1971; Urrejola y Orellana 2000). A su vez, este amplio eje altitudinal contempla un margen para evaluar el posible acceso de grupos costeros a áreas fuente localizadas a mayor distancia hacia el interior y a campamentos localizados en el faldeo occidental de la cordillera de Domeyko, a distancias superiores a $100 \mathrm{~km}$ lineales de la costa (Cabello 2008).

Por su parte, la escala temporal cubre desde 12.000 hasta $1.500 \mathrm{cal}$. AP, incluyendo el Período Formativo (Castelleti 2007) debido a la continuidad que se ha observado en el modo de vida cazador-recolector-pescador arcaico en el área de estudio y su tardía integración -de manera más sostenida e intensa - en redes de interacción con comunidades agropastoriles de valles y oasis interiores (Núñez 1984; Salazar et al. 2015). Estas condiciones avalarían el predominio, o exclusividad, de dinámicas de aprovisionamiento directo desde los asentamientos costeros durante el rango temporal definido, justificando, a su vez, el abordaje del Período Arcaico de manera global.

\section{* Teledetección espacial, espectroscopía y Sig PARA EL RASTREO REMOTO DE FUENTES LÍTICAS Y SUS RUTAS DE ACCESO}

La localización de las áreas fuente de procedencia de los principales tipos de materias primas silíceas y silicificadas registradas en los contextos arcaicos de Taltal, y de los rasgos formales asociados a la movilidad dirigida hacia ellas, constituye un desafío metodológico por dos aspectos centrales. Por una parte, la extensión de los terrenos involucrados vuelve inviable, por limitaciones de tiempo y recursos de los proyectos de investigación actuales, la realización de prospecciones pedestres sistemáticas de una cobertura espacial adecuada a la problemática de estudio. Esta situación se torna crítica en caso de no contar con criterios rectores para la definición de áreas de interés específicas. Por otra parte, la alta variabilidad macroscópica de las rocas silíceas y silicificadas dificulta la discriminación visual entre sus distintos tipos, exigiendo en estudios de procedencia de estas materias primas la implementación de técnicas lentas, costosas y/o destructivas, como la activación neutrónica, difracción o fluorescencia de rayos $\mathrm{X}$, espectrometría de masas y estudios petrográficos de 
secciones delgadas (Hubbard et al. 2005; Parish 2011). Cabe aclarar que estas técnicas, a su vez, no constituyen métodos probados para el estudio de procedencia de sílices, dado el alto nivel de complejidad de este tipo de rocas (Luedtke 1979, Crandell 2006) y la carencia de estudios geológicos específicos que permitan entender la diagénesis local de las mismas.

Estas condiciones son particularmente restrictivas en regiones donde se registran distintos afloramientos y múltiples tipos de rocas silíceas y silicificadas con rasgos macroscópicos compartidos, para los cuales no se dispone de datos geológicos de procedencia (Parish 2013) y solo existe información arqueológica fragmentaria. La localidad de Taltal correspondería a una de estas regiones, ya que, por una parte, cuenta con una investigación arqueológica centrada históricamente en la franja litoral $y$, por otra, con una data reducida de la amplia zona de la Depresión Intermedia, caracterizada por registros arqueológicos espacialmente acotados, con niveles de detalle variables y criterios no unificados para la clasificación de sitios y materias primas, constituidos fundamentalmente por estudios de impacto ambiental.

Ante este escenario, se plantea la necesidad de implementar herramientas que hagan posible abordar de manera extensiva la geología y topografía del área de estudio, con el fin de localizar de manera remota las potenciales áreas fuente líticas y corredores de movilidad entre la costa y la Depresión Intermedia de Taltal. Este abordaje se plantea como una estrategia orientada a facilitar el diseño de prospecciones pedestres dirigidas y el estudio sistemático de aquellos espacios en los que se desarrollaron dinámicas de explotación, procesamiento y traslado de recursos líticos no-locales. En los siguientes apartados se detallan las técnicas de análisis geofísico y geoespacial consideradas pertinentes para la consecución de dichos objetivos.

\section{Espectroscopía de reflectividad}

La espectroscopía de reflectividad en el rango visible a infrarrojo cercano (VIS/NIR -o VNIR-: 0,35-2,5 ctm) (Clark 1999) se destaca como una técnica precisa, veloz, eficiente en términos de costo y no destructiva para rastrear fuentes líticas (Hubbard et al. 2005; Parish 2011).
Asumiendo que la asignación de un tipo de roca a una fuente específica de origen (o sourcing) constituye un problema de probabilidad estadística, debido a la existencia de una alta heterogeneidad a nivel físico y composicional dentro de la mayoría de las fuentes de rocas silíceas (Luedtke 1979; Shackley 2008), desarrollar estrategias de muestreo exhaustivo resulta clave para abordar la variabilidad vertical y horizontal derivada de procesos paleoambientales y post-depositacionales que incidieron en la formación de estas fuentes (Parish 2011).

La espectroscopía VNIR hace posible un análisis rápido y a la vez detallado de las propiedades de reflectividad de un gran volumen de muestras líticas, permitiendo cuantificar los rangos de variabilidad que caracterizan a una determinada fuente y así mejorar el nivel de resolución geográfica y geológica de los estudios de procedencia (Parish 2011). Los resultados experimentales del empleo de esta técnica demuestran su capacidad para diferenciar con certeza entre rocas silíceas y no silíceas, pero también entre tipos de rocas silíceas macroscópicamente similares, con un alto porcentaje de acierto (98\%) en la asignación de las muestras analizadas a sus respectivas categorías de pertenencia (Hubbard et al. 2005). Esta capacidad ha sido explotada con éxito para discriminar a escala local y regional entre tipos de chert originados en distintas formaciones geológicas, diferenciando, a su vez, aquellas rocas silíceas procedentes de afloramientos distantes pero pertenecientes a una misma formación geológica (Parish 2011).

\section{Teledetección satelital}

El potencial de esta técnica radica en su aptitud para la observación de rasgos y fenómenos que comprometen amplios territorios, gracias a la perspectiva vertical y panorámica que aportan las capturas realizadas a gran altitud desde plataformas espaciales en la órbita terrestre. Pero también en la capacidad de los sensores espaciales de obtener información en diferentes anchos de banda del espectro electromagnético (EEM), es decir, de registrar distintas formas de energía -o radiación- que no se restringen al rango visible (Chuvieco 2006).

Imágenes satelitales multiespectrales de resolución media como las del proyecto Landsat, corresponden a escenas que cubren un área de $185 \times 185 \mathrm{~km}$ e incorporan hasta 11 bandas espectrales en el rango visible a infrarrojo 
medio (en el caso de las más recientes Landsat 8) (USGS). Mediante el empleo de software de procesamiento digital de imágenes, la información espectral contenida en las escenas Landsat puede ser combinada de diferentes maneras con el fin de mejorar su nitidez y contraste, facilitando así su interpretación visual (Chuvieco 2006).

A su vez, los datos espectrales contenidos en las imágenes Landsat pueden ser sometidos a análisis estadísticos para agrupar los pixeles de la escena en categorías de interés dentro de una clasificación temática - o supervisada-. Mediante esta técnica de procesamiento o interpretación digital la información de la imagen es organizada en agrupamientos o clusters de pixeles que representan tipos de cobertura de suelo similares en términos de sus patrones espectrales (Parcak 2009). Esta estrategia ha sido aplicada exitosamente en ambientes desérticos para el mapeo litológico, permitiendo la discriminación de formaciones rocosas superficialmente expuestas a partir de sus propiedades de reflectividad (Sultan et al. 1987; Amer et al. 2009).

Las imágenes Landsat han tenido el uso más amplio en arqueología de entre todos los tipos de imágenes satelitales (Parcak 2009). Al ser incorporadas en investigaciones a escala regional, estas imágenes han aportado a la elaboración de mapas temáticos destinados a resaltar zonas específicas de extracción de recursos líticos en tiempos prehistóricos (Carr y Turner 1996) o con afloramientos rocosos potencialmente explotados en el pasado, estableciendo directrices para el diseño y ejecución de campañas de prospección focalizadas (Rosandahl 2010).

\section{Espectroscopía de reflectividad y teledetección satelital}

En el mapeo litológico, análisis espectroradiométricos de muestras de rocas (en laboratorio o en campo) han hecho posible refinar la clasificación temática de las imágenes satelitales Landsat, gracias al uso de datos de reflectividad derivados del trabajo en terreno como un medio para depurar las huellas espectrales de las unidades litológicas que se buscaba mapear a partir del estudio de imágenes satelitales, distinguiéndolas efectivamente de otras formaciones geológicas o cubiertas de suelo circundantes (Sultan et al. 1987; Leverington y Moon 2012).
En arqueología, en tanto, el uso complementario de espectroscopía de reflectividad basada en datos de terreno ("ground-truth" data) y clasificaciones temáticas de imágenes Landsat ha demostrado ser una estrategia metodológica capaz de mapear áreas de explotación prehistórica de rocas silíceas (Carr y Turner 1996). Esto gracias a que los datos derivados de análisis espectroscópicos de muestras líticas de terreno, al aportar información específica de formaciones rocosas en su expresión geomorfológica superficial, contribuyen a la definición y refinamiento de firmas de clases espectrales que posteriormente pueden ser pesquisadas de manera remota mediante el procesamiento digital de las imágenes multiespectrales Landsat (Carr y Turner 1996; Rosendahl 2010).

\section{SIG y modelos de movilidad}

Las aproximaciones a las formas de movilidad a través de modelamientos en plataformas SIG han sido una de las líneas más fructíferas de la aplicación de esta tecnología en análisis arqueológicos, centrándose tradicionalmente en aspectos concretos de la movilidad, como son los caminos y senderos (Fábrega-Álvarez et al. 2011). Este tipo de análisis sostiene una relación entre el registro arqueológico y la estructura potencial de un territorio para el desplazamiento, la que es pesquisada a través de un modelo explícito: digital y matemático (Fábrega-Álvarez et al. 2011).

Si bien es posible sostener que la capacidad humana de movimiento y las condicionantes del terreno para el desplazamiento (fundamentalmente la topografía) no han variado significativamente en el tiempo en ambientes hiperáridos, es necesario tener en cuenta que la movilidad es un fenómeno que no puede ser únicamente explicado en términos de esfuerzo. El movimiento y su traducción material, los caminos o senderos, no surgen aleatoriamente en el espacio, sino en función de la necesidad de hacer permeable un territorio a través de la comunicación física entre determinados puntos del mismo (Parcero-Oubiña y Fábrega-Álvarez 2006; Fábrega-Álvarez et al. 2011).

En este caso de estudio en particular, la identificación de posibles fuentes primarias de materias primas líticas de alta calidad se integra dentro de una óptica que contempla estas formaciones geológicas discretas como nodos de atracción (Wilson 2007) para los pobladores 
costeros y ve, en el estudio conjunto de su distribución espacial y la topografía local, el potencial para definir zonas de convergencia que encauzaron la movilidad desde los asentamientos litorales hacia ellas, facilitando así la identificación de rutas o corredores de tránsito pedestre arcaicos (Fábrega-Álvarez 2011; Llobera et al. 2011).

\section{^ Propuesta metodológica}

En los siguientes apartados se detallan las etapas y procedimientos específicos que dan forma a la presente propuesta metodológica. Se delinea una aproximación al paisaje lítico de Taltal que despliega técnicas de análisis geofísico para el análisis de conjuntos líticos arcaicos y la localización de sus fuentes de procedencia, para posteriormente realizar modelamientos SIG dirigidos a relevar la estructura de movilidad de este paisaje en función de la localización y características diferenciales de las principales áreas de aprovisionamiento lítico detectadas.

\section{Obtención de muestras, clasificación petrográfica- macroscópica y análisis de firmas espectrales líticas}

Con el fin de aproximarse a la caracterización del universo de materias primas líticas silíceas y silicificadas presentes en los contextos arqueológicos de Taltal, se realizarán estudios de espectroscopía de reflectividad de muestras de material lítico (específicamente lascas) obtenidas de: 1) depósitos correspondientes a diversos momentos de la secuencia arcaica local, derivados de estudios cronoestratigráficos controlados en sitios costeros; 2) sitios de procesamiento lítico de carácter discreto, definidos por dispersiones superficiales acotadas de nódulos y desechos de talla lítica registrados en la Depresión Intermedia; y 3 ) fuentes primarias de rocas silíceas y silicificadas detectadas en el segmento central e interior de la Depresión Intermedia (afloramientos/canteras de cerro Punta Amarilla, sector Pampa Yolanda Norte, y un lomaje bajo a $3,5 \mathrm{~km}$ al norte del cerro Guanaco, sector de Pampa Altamira, respectivamente). ${ }^{16}$

En una primera etapa, se realizará la recolección superficial en los sitios discretos de procesamiento, así como la selección de muestras líticas de los depósitos estratigráfi-

16 Las muestras y registros señalados han sido trabajados por los proyectos FONDECYT 1080666 y 1110196 y su estudio se profundizará en el proyecto FONDECYT 1151203, actualmente en curso. cos costeros, procurando abarcar el rango acumulativo de variabilidad de las materias primas representadas en estas locaciones (Parish 2011). Esta recolección y selección se regirá por los criterios definidos por análisis petrográficos a visu ejecutados en el marco del proyecto FONDECYT $1151203 .{ }^{17}$ En tanto, la obtención de muestras líticas de las áreas fuente responderá a una estrategia de muestreo sistemático a partir de transectas y colectas a intervalos regulares, para caracterizar la variabilidad vertical y horizontal de los materiales de cada afloramiento/ cantera (Parish 2011).

Posteriormente, en los laboratorios del Servicio Geológico Minero Argentino (SEGEMAR) se llevarán a cabo análisis espectroscópicos en condiciones controladas con un espectrorradiómetro de alta resolución (modelo SVC HR-1024i), con capacidad de cubrir todo el espectro de reflectividad VNIR (0,35-2,5 ctm). Las mediciones se realizarán sobre muestras de las categorías generales de material lítico silíceo y silicificado derivadas del análisis petrográfico-macroscópico de los tres tipos de contexto arriba detallados (sitios costeros, sitios de procesamiento intermedio y afloramientos/canteras). Esto permitirá acotar las muestras a conjuntos estadísticamente coherentes en términos de sus perfiles espectrales. Dentro de cada categoría lítica general se procurará incluir especímenes con distinto grado de patinación y porcentaje de corteza para relevar rasgos de absorción potencialmente diagnósticos y conformar un catálogo espectral lo más exhaustivo posible de las materias primas de grano fino de cada contexto en estudio (Hubbard et al. 2005).

Aquellas categorías consolidadas luego del procesamiento estadístico de los resultados de los análisis espectroscópicos en laboratorio (Clark 1999, Hubbard et al. 2005; Parish 2011), serán integradas como firmas de clases espectrales en una clasificación supervisada y rastreadas mediante una estrategia de teledetección satelital (Carr y Turner 1996; Rosendahl 2010), cuyas características se detallan a continuación.

17 Este análisis petrográfico-macroscópico pondera atributos de color, translucencia, lustre, patrón y textura de las piezas líticas, definiendo de esta manera categorías generales de materias primas silíceas y silicificadas presentes en los distintos contextos en estudio (Crandell 2006). 


\section{Teledetección satelital de fuentes primarias de materias primas líticas}

La detección de potenciales fuentes primarias de material lítico de grano fino en la Depresión Intermedia de Taltal se realizará sobre la base de imágenes multiespectrales Landsat 8 OLI, las cuales serán procesadas con herramientas del software ERDAS Imagine ${ }^{\circledR} 2014$ para su corrección atmosférica y la obtención de una imagen única que cubra exclusivamente el polígono que delimita el área de estudio. Sobre la base de esta imagen multiespectral corregida y recortada, se implementará una clasificación multiespectral supervisada (Chuvieco 2006; Parcak 2009).

En esta etapa, la clasificación supervisada se basará en datos de reflectividad procedentes de dos fuentes. Por una parte, se utilizarán las firmas espectrales de las categorías de rocas silíceas y silicificadas derivadas de mediciones espectroscópicas en laboratorio. Por otra, se emplearán los archivos de firma espectral generados por el software ERDAS a partir de áreas de interés, correspondientes a polígonos trazados sobre las imágenes satelitales, los que delimitarán áreas con tipos específicos de coberturas de suelo reconocidas y mapeadas en terreno. Entre estas áreas de interés se incluirán preliminarmente las dos zonas de afloramiento/cantera de rocas silíceas y silicificadas documentadas a la fecha dentro del área de estudio (Pampa Yolanda Norte y Pampa Altamira), y sectores de suelos desnudos o pedregosos sin registro de este tipo de rocas en superficie, cuidando de abarcar con los polígonos definidos una cantidad suficiente de pixeles para obtener archivos de firma espectral representativos (Van Niel et al. 2005).

Luego de seleccionadas las áreas de interés y generados los archivos de firma espectral de las distintas clases de referencia a pesquisar, la clasificación supervisada se llevará a cabo utilizando un clasificador de máxima semejanza (Rosendahl 2010; Conroy et al. 2012). Este proceso agrupará los pixeles de la imagen multiespectral Landsat en las clases establecidas como relevantes para la investigación y producirá un mapa temático del área de estudio en el que se resaltarán las formaciones geológicas con potenciales fuentes primarias de rocas de alta calidad para la talla (Carr y Turner 1996; Rosendahl 2010).

\section{Testeo preliminar de la estrategia de teledetección satelital y registro en terreno}

Como una manera de contrastar de manera inicial los resultados de la estrategia de teledetección satelital implementada, se ejecutarán prospecciones arqueológicas dirigidas a la exploración selectiva de algunas de aquellas áreas identificadas de manera remota como potenciales fuentes primarias de materias primas silíceas y silicificadas, procurando registrar al menos una fuente de cada categoría de roca detectada.

En terreno se empleará una grilla regular de transectas cada $50 \mathrm{~m}$ para la prospección y se privilegiará una estrategia de registro rápido, basado en el geoposicionamiento de las entidades arqueológicas detectadas mediante el uso de una codificación simple, orientada a dar cuenta de la distribución espacial y características generales de las evidencias materiales en los contextos de explotación lítica estudiados. Esta estrategia, además de agilizar el trabajo en terreno, facilitará el posterior procesamiento de datos en SIG (Mayoral et al. 2009).

El registro en campo contempla el relevamiento de información relativa a los factores geográficos o geológicos de las fuentes de rocas localizadas, específicamente sus dimensiones (delimitación horizontal) y abundancia, en términos del tamaño y densidad de nódulos o piezas líticas (Wilson 2007).

Muestreos sistemáticos de piezas líticas se ejecutarán en cada una de las fuentes líticas localizadas para abordar su variabilidad vertical y lateral, además de evaluar experimentalmente la calidad para la talla de las distintas materias primas presentes en el área de estudio (Galarce 2014). Estas nuevas muestras serán objeto de mediciones espectro-radiométricas en laboratorio dirigidas a perfeccionar el análisis de teledetección satelital.

\section{Refinamiento de la clasificación supervisada y generación de catálogos espectrales}

En esta etapa se buscará refinar la estrategia de rastreo remoto de fuentes líticas a través de una nueva clasificación supervisada, que incorporará como áreas de interés los polígonos cubiertos por las fuentes primarias de rocas silíceas y silicificadas mapeadas en terreno, además de los 
archivos de firma espectral derivados de mediciones en laboratorio de las muestras de materias primas sistemáticamente recolectadas en ellas.

Integrando estos nuevos datos de terreno y laboratorio, se depurará la clasificación temática de la imagen Landsat, resaltarán las zonas de explotación prehispánica de materias primas silíceas y silicificadas documentadas, $y$, eventualmente, detectarán fuentes primarias y secundarias no discriminadas por el modelo predictivo inicial. Esto gracias a la incorporación, en los análisis de detección remota, de un mayor acervo de data espectral de detalle, característica de la litología del área de estudio.

Las firmas espectrales de aquellas rocas recuperadas de cada fuente lítica, dadas las condiciones sistemáticas de su muestreo, contribuirán a la formación de catálogos espectrales exhaustivos, los cuales quedarán disponibles como material de consulta para futuras investigaciones.

Adicionalmente, en esta etapa se realizará el cruce en una plataforma SIG (software ArcGIS $10^{\circledR}$ ) de los datos georreferenciados de localización y caracterización de las áreas fuente detectadas, y aquellos disponibles en cartas geológicas de detalle de la zona de estudio. Esto con el propósito de evaluar su concordancia y pesquisar la pertenencia de las áreas fuente a tipos de formaciones geológicas particulares previamente documentadas por estudios especializados.

\section{Integración de los datos espaciales y modelamientos de movilidad en SIG}

Se llevarán a cabo análisis de movilidad empleando herramientas del software ArcGIS $^{\circledR} 10$ y modelos digitales de elevación ASTER GDEM y SRTM. Se calcularán superficies de coste (o de fricción) en función de la topografía local, sobre las cuales se generarán modelos de movilidad que se valen de herramientas de análisis hidrológico para determinar flujos óptimos de desplazamiento por el terreno (Fábrega-Álvarez 2006), considerando como puntos de destino las áreas fuente de materias primarias localizadas previamente.

Se trata de un modelo que permite relevar redes de movilidad óptima hacia cada fuente lítica desde cualquier punto del área de estudio, sin requerir de un punto de origen predeterminado (Llobera et al. 2011). Al ser analizadas en conjunto, la superposición de estas redes hace posible distinguir corredores potenciales de movimiento que reflejan condiciones diferenciales de accesibilidad a las fuentes líticas (Fábrega-Álvarez 2006), lo cual brinda la posibilidad de acotar las áreas de búsqueda en terreno de aquellas rutas de movilidad y sitios de relevo que las comunicaron entre sí y las articularon con asentamientos costeros.

En esta etapa final, los modelamientos de movilidad hacia las áreas fuente de rocas silíceas y silicificadas serán cruzados con la información georreferenciada de sitios discretos de explotación y procesamiento lítico de la Depresión Intermedia de Taltal, como una vía de aproximación a las distancias de transferencia, los tiempos (jornadas de viaje) y orientación (selectividad en el uso de fuentes líticas) implicados en los desplazamientos pedestres costa-pampa.

\section{* Resultados preliminares y discusión}

Con el propósito de evaluar la aplicabilidad de la propuesta metodológica anteriormente detallada en el contexto arqueológico en estudio, se realizaron análisis sobre imágenes multiespectrales Landsat 8 OLI con herramientas del software ERDAS Imagine ${ }^{\circledR} 2014$, los que incluyeron procesamientos digitales para su corrección atmosférica, mejoramiento y realce, mapeo de materiales y clasificación supervisada. La implementación de estas técnicas se centró en la identificación, de manera remota, de la localización de formaciones geológicas potencialmente portadoras de rocas silíceas y silicificadas dentro del área de estudio. Los resultados de estos análisis preliminares se detallan a continuación y discuten brevemente en relación a antecedentes geológicos y arqueológicos locales.

Las tareas iniciales de procesamiento de las imágenes satelitales correspondieron a la conversión a valores de reflectividad (corrección atmosférica) de la data espectral contenida en las cuatro escenas Landsat necesarias para cubrir el área de trabajo. ${ }^{18}$ Posteriormente, las escenas Landsat corregidas fueron fusionadas en un mosaico del cual se extrajo el polígono del área de estudio. Los sub-

18 Para esta transformación de los datos digitales a parámetros físicos, se empleó el modelo ATCOR ${ }^{\circledR}{ }^{\circledR}$, excluyendo la banda pancromática (8), de detección de nubes cirrus (9) y las bandas térmicas (10 y 11 ). 


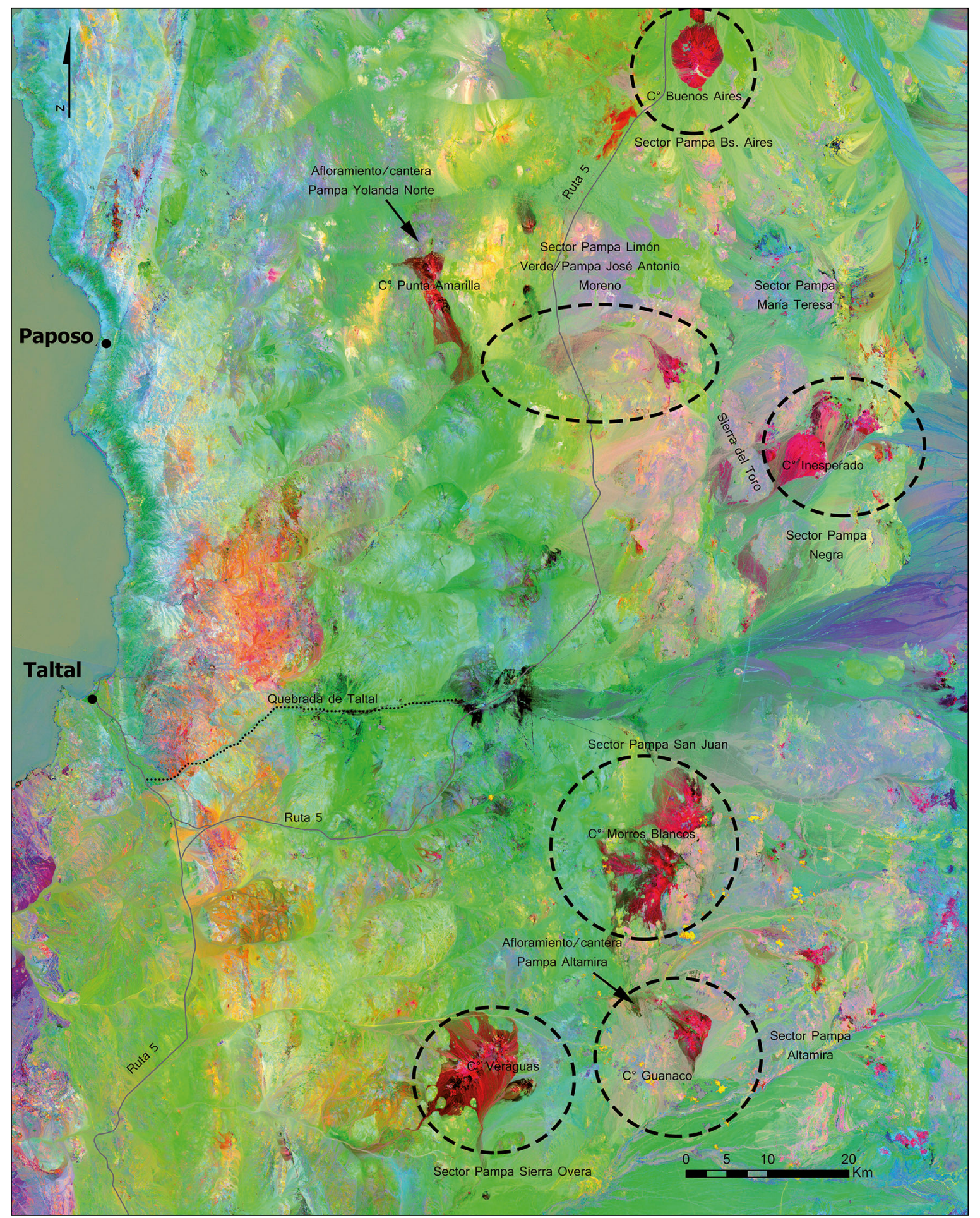

Figura 2. Imagen satelital Landsat 8 procesada del área de estudio mediante análisis de componentes principales. Composite de "falso color" CP 6-4-5. En tono rojo a fucsia y en ciertos casos verde oscuro, se destacan las formaciones geológicas potencialmente portadoras de sílices. 
secuentes análisis se llevaron a cabo sobre esta imagen multiespectral de $30 \mathrm{~m}$ de resolución espacial y siete bandas. Específicamente éstas corresponden a las siete primeras bandas captadas por el sensor Landsat 8, las que cubren el rango VNIR entre los 0,43 y $2,29 \mathrm{ctm}$ (USGS).

\section{Mejoramiento digital de la imagen}

El primer producto procesado a partir de la imagen base fue un análisis de componentes principales o PCA, dirigido a reducir los datos espectrales redundantes contenidos en las distintas bandas Landsat a un conjunto acotado de nuevas bandas (componentes) no correlacionadas $^{19}$ (Chuvieco 2006). La escena procesada fue luego objeto de mejoras de resolución espacial a través de su fusión con un mosaico de escenas pancromáticas Landsat de área de estudio. Esta técnica, denominada pansharpening, permitió obtener una imagen multiespectral de 15 $\mathrm{m}$ de resolución y se llevó a cabo empleando el método HPF (High-Pass Filter) (Chávez et al. 1991).

Mediante combinaciones de los componentes principales (CP) generados, se facilitó la discriminación de las distintas coberturas de suelo presentes en el área de estudio a partir del realce de contrastes en la escena (Amer et al. 2009; Parcak 2009; Rosendahl 2010). Resultó de mayor utilidad en este sentido el composite RGB con los CP 6, 4 y 5 dispuestos en los canales rojo, verde y azul, respectivamente. En este composite de "falso color", los dos sectores de afloramiento/cantera de rocas silíceas y silicificadas registrados en terreno (Pampa Yolanda Norte y Pampa Altamira) se destacan contrastando fuertemente como áreas de color rojo a fucsia intenso -y en casos puntuales verde oscuro- dentro de la imagen (Figura 2).

En la escena procesada mediante PCA no solo es posible distinguir las anteriormente señaladas áreas fuente líticas, sino que se aprecian formaciones rocosas similares en cuanto a sus rasgos espectrales en dos grandes sectores relativamente próximos a ellas. El primero de estos sectores se ubica al este de Pampa Yolanda Norte, comprometiendo, por un lado, terrenos de Pampa Limón Verde, Pampa José Antonio Moreno, Pampa María Teresa (sector norte de Sierra del Toro) y Pampa Negra (cerro Inesperado), y, por otro, el cerro Buenos Aires en la pam-

19 En este caso se seleccionaron seis componentes principales (el $n$ de bandas originales de la imagen menos 1). pa homónima, ubicado a la altura de la Ruta $5,30 \mathrm{~km}$ al norte del sector anterior.

El segundo sector principal destacado en la escena mejorada se relaciona al área fuente documentada en Pampa Altamira, donde, en un radio de $30 \mathrm{~km}$ en torno al referido afloramiento/cantera, se distinguen tres cerros potencialmente portadores de sílice, uno en Pampa San Juan (cerro Morros Blancos), otro de menor envergadura en Pampa Altamira, inmediatamente al noreste de cerro Guanaco, y finalmente el cerro Veraguas, en Pampa Sierra Overa.

Un último rasgo a precisar respecto a esta primera imagen procesada se refiere a la correspondencia de los ceros destacados como posibles áreas fuente de materias primas silíceas y silicificadas con formaciones geológicas específicas. Esto debido a que una revisión preliminar de la información geológica de la zona ${ }^{20}$ identifica esos sectores como terrenos dominados por secuencias y complejos volcánicos continentales (SERNAGEOMIN 2003), lo que daría cuenta de su potencial como formaciones portadoras de rocas de alta calidad para la talla.

\section{Perfiles espectrales y mapeo de materiales}

El mapeo de materiales es una herramienta del módulo Spectral Analysis del software ERDAS Imagine ${ }^{\circledR}$, con la capacidad de rastrear dentro de la imagen multiespectral base la presencia de zonas con materiales específicos, basándose en los perfiles espectrales de aquellos materiales definidos como objetivo (o target) de la búsqueda. Como resultado, el análisis arroja una imagen en escala de grises cuyos pixeles tienen valores que representan un estimado de la concentración de los materiales de interés en ellos. Por lo tanto, los contrastes de la imagen darían cuenta de la presencia diferencial de estos materiales dentro del área de estudio.

Los perfiles espectrales (o espectros) de los materiales target pueden ser obtenidos de librerías espectrales ${ }^{21} \mathrm{o}$

20 Cobertura digital base geológica escala 1:1.000.000, SERNAGEOMIN.

21 Las librerías o bibliotecas espectrales contienen colecciones de espectros de reflectividad de distintos materiales terrestres, registrados con espectrorradiómetros en condiciones controladas de laboratorio (Chuvieco 2006). 


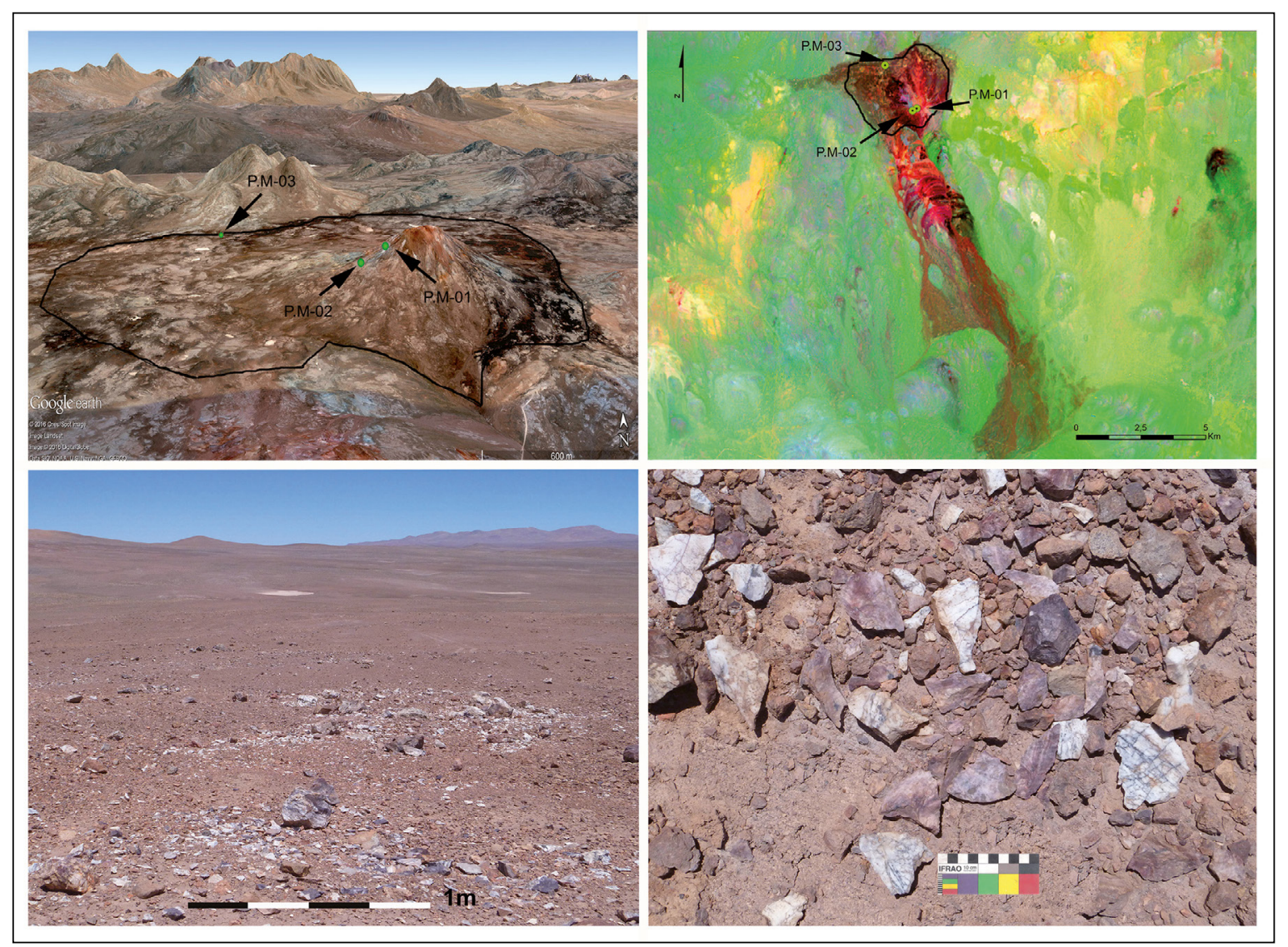

Figura 3. Imágenes generales y vistas de detalle de los puntos de muestreo y polígono de delimitación en el sector de afloramiento/cantera de Pampa Yolanda Norte (cerro Punta Amarilla).

derivados de la información contenida en los pixeles de la escena en estudio. En este caso se siguió la segunda alternativa, debido a que no existe a la fecha información espectral de los distintos tipos de roca registrados en el área de trabajo.

Los pixeles de muestreo seleccionados para la obtención de espectros correspondieron a puntos georreferenciados en terreno en los cuales se documentaron concentraciones de nódulos y derivados de talla sobre rocas silíceas y silicificadas con una alta densidad de piezas líticas. Se utilizaron tres puntos registrados dentro del aforamiento/cantera de Pampa Yolanda Norte (cerro Punta Amarilla) y tres de aquel identificado en el sector de Pampa Altamira (Figuras 3 y 4). Estudiando los espectros muestreados en estos dos sectores de afloramiento/cantera fue posible evaluar la consistencia de las medidas (perfiles espectrales) obtenidas dentro de cada uno de ellos.
Considerando estos antecedentes, para el análisis de mapeo de materiales se trabajó con un espectro promediado de los puntos de muestreo obtenidos en las dos zonas de afloramiento/cantera, estrategia que demostró ser adecuada para contrastar aquellas fuentes primarias de rocas silíceas y silicificadas en el área de estudio con características espectrales similares a las registradas a la fecha, evitando los sesgos que implicarían búsquedas basadas exclusivamente en los datos de una u otra fuente (Figura 5).

Los resultados del mapeo de materiales realizado ratifican, en gran medida, aquellos derivados de la interpretación visual de la imagen procesada mediante PCA, al destacar en tonos oscuros más intensos los sectores anteriormente referidos como terrenos con formaciones geológicas potencialmente portadoras de rocas silíceas y silicificadas. 


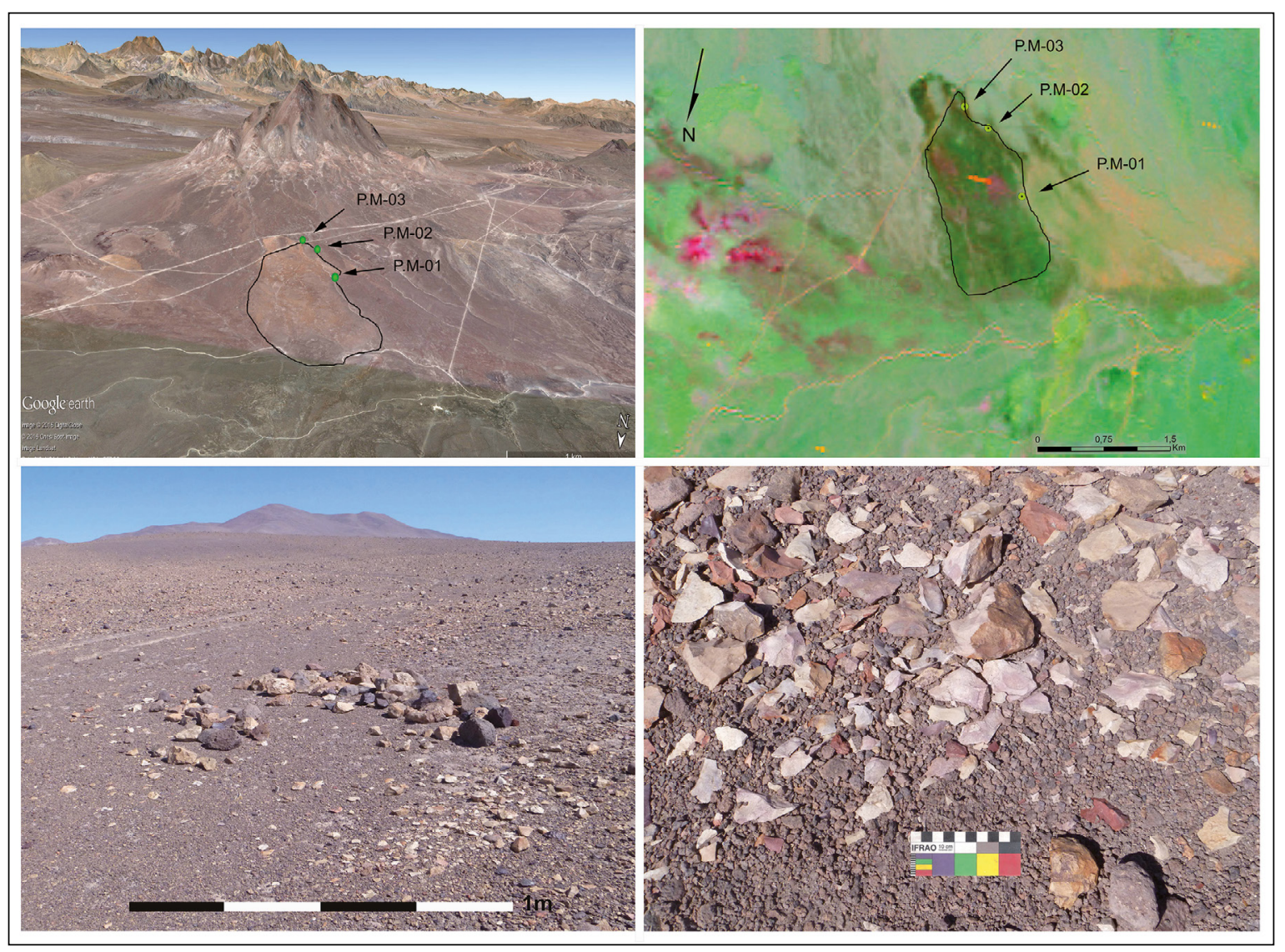

Figura 4. Imágenes generales y vistas de detalle de los puntos de muestreo y polígono de delimitación en el sector de afloramiento/cantera de Pampa Altamira.

La imagen generada por el mapeo de materiales es elocuente al situar el tipo de formaciones geológicas de interés en una franja longitudinal que se extiende por el segmento central de la Depresión Intermedia de Taltal, específicamente entre 45 y $90 \mathrm{~km}$ lineales al este de la actual línea de costa. Esta situación será discutida a continuación a la luz de los resultados obtenidos del proceso de clasificación supervisada del área de trabajo, discusión en la que se integran antecedentes generales de la geología del área de estudio y datos derivados de la sistematización de hallazgos de sitios de procesamiento lítico reportados por estudios de impacto ambiental y reconocimientos realizados por el equipo investigador en la zona.

\section{Clasificación supervisada, geología y el registro arqueológico al interior de Taltal}

El último análisis de teledetección satelital implementado correspondió a una clasificación supervisada de la imagen base. Este proceso requirió de la definición de áreas de interés o entrenamiento representativas de los tipos específicos de cobertura de suelo que formarían parte de la clasificación supervisada. Para ello se consideró apropiada una estrategia que integró: 1) el conocimiento de terreno de los investigadores (puntos georreferenciados durante reconocimientos vehiculares y pedestres); 2) la inspección de imágenes satelitales de alta resolución espacial (exploradas con Google Earth Pro ${ }^{\circledR}$ ); y 3 ) el análisis visual de la escena Landsat 8 procesada a través de PCAypansharpening. 


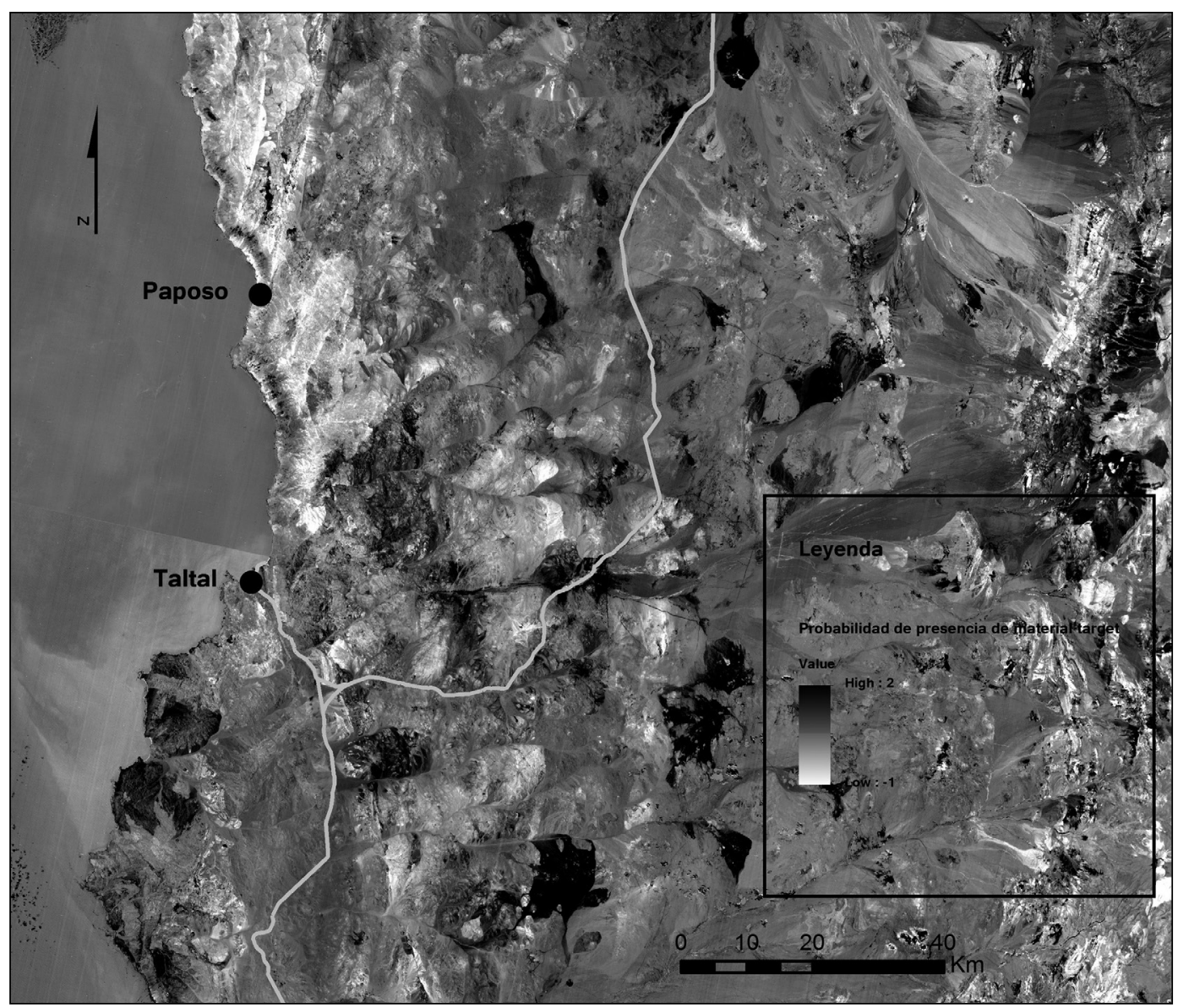

Figura 5. Imagen satelital Landsat 8 del área de estudio procesada con la técnica de mapeo de materiales. En negro se destacan las formaciones geológicas potencialmente portadoras de sílices.

Las clases de cobertura utilizadas en esta clasificación supervisada fueron tres: océano; suelos y/o formaciones rocosas sin presencia de sílices; y formaciones geológicas portadoras de rocas silíceas-silicificadas. En el último caso se emplearon como áreas de entrenamiento, polígonos trazados en torno a las fuentes primarias de este tipo de rocas, específicamente aquellas documentadas en Pampa Yolanda Norte y Pampa Altamira (Figuras 3 y 4 ).

La imagen clasificada resulta de más simple lectura a raíz de su reducción a unas pocas clases de interés, condición que contrasta con los matices ofrecidos por la gradación en tonos de grises de las imágenes derivadas del mapeo de materiales y de color en el caso de aquellas procesadas con PCA (Figuras 6 y 7). La interpretación de esta imagen simplificada debe ser abordada con cautela, pues, a diferencia del método de muestreo a nivel de pixel utilizado en el mapeo de materiales, el uso de amplios polígonos para la definición de las clases de cobertura de suelo implica el manejo de datos espectrales promediados de una gran cantidad -y potencial diversidad- de pixeles contenidos en esas áreas, lo que puede introducir "ruido" en los archivos de firma espectral empleados por el clasificador. Es por ello que la clasificación supervisada es considerada en el marco de la propuesta metodológica presentada, como un proceso que necesariamente debe ser refinado mediante la integración de datos obtenidos a través de análisis espectroscópicos de muestras líticas en laboratorio y de prospecciones dirigidas a áreas fuente. De esta manera podrían ser ratificados o descartados como áreas de interés, sectores con pixeles dispersos que han sido asignados en la actual clasificación a la categoría de formación geológica portadora de sílices. 


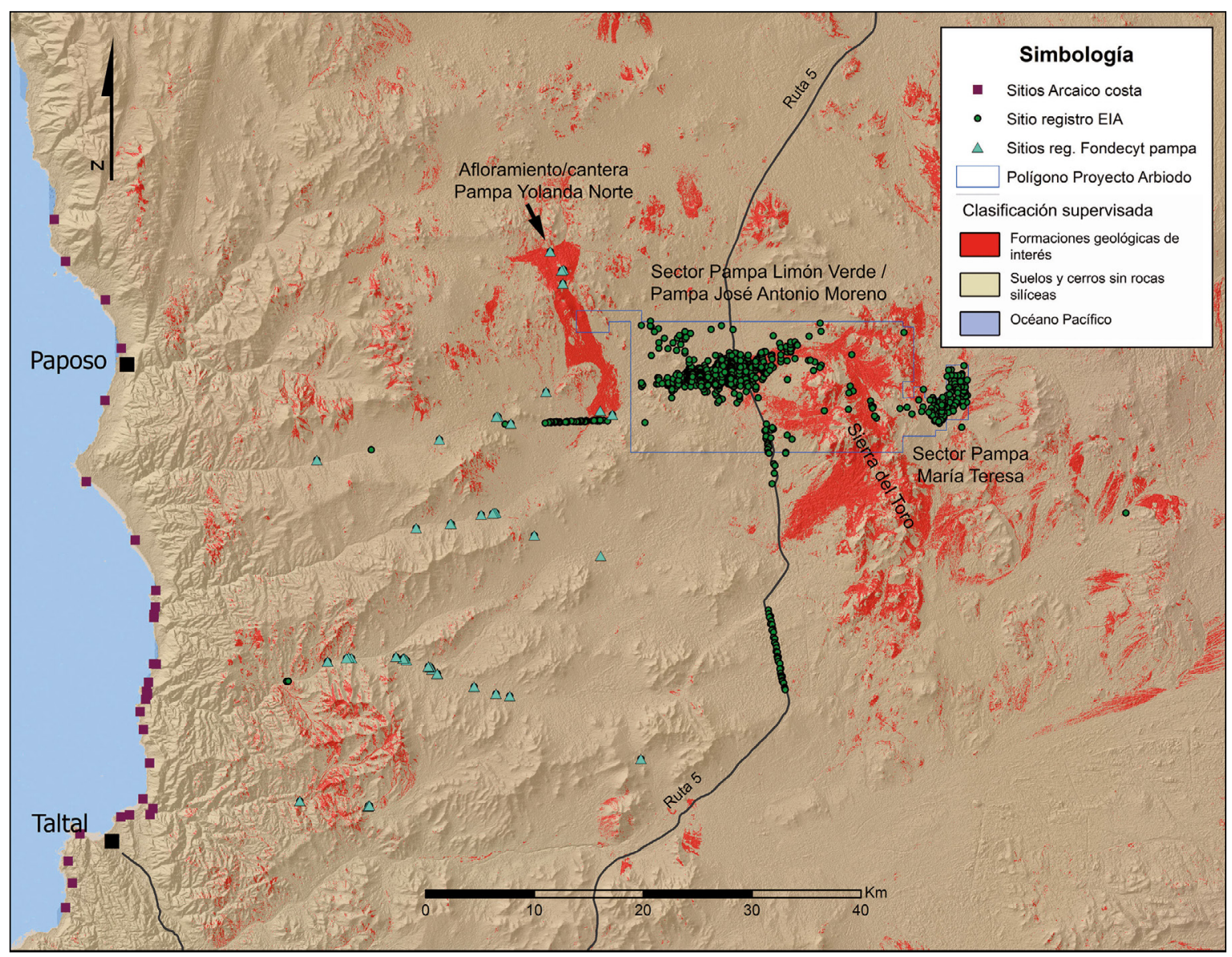

Figura 6. Detalle del segmento norte de la imagen clasificada Landsat 8 del área de estudio con el detalle de sus principales sectores y los sitios arqueológicos registrados.

Tomando en cuenta los posibles sesgos introducidos en esta clasificación supervisada preliminar, es significativa la congruencia de los resultados arrojados por ella con las imágenes derivadas de los análisis previos, en términos de la distribución espacial diferencial de las formaciones geológicas potencialmente portadoras de rocas de alta calidad para la talla, lo cual justifica su interpretación en conjunto con los registros arqueológicos sistematizados para el área y los antecedentes proporcionados por una revisión general de coberturas geológicas de la misma.

De manera sintética, cabe precisar que los registros arqueológicos prehispánicos o con componente prehispánico en el área de estudio suman un total de $1272 .^{22}$

22 Estos registros se clasificaron en categorías funcionales, en acuerdo con las descripciones de los componentes materiales,
De ellos, 1264 corresponden a sitios con presencia de talla lítica, donde se evidencia el desbaste de nódulos o matrices, sitios que se desglosan en dos grupos principales: eventos de talla $(47,23 \%)$ y conjuntos de eventos de talla (29,83\%), los cuales pueden encontrarse con o sin asociación a bloques erráticos o estructuras subcirculares de piedra (Figura 8). Estos contextos de procesamiento lítico de la Depresión Intermedia, en concordancia con los antecedentes arqueológicos reseñados anteriormente, demuestran que el registro de materias primas silíceas es marcadamente predominante (93\%). ${ }^{23}$

tamaño del sitio y número de piezas, señaladas en las fichas de registro de los distintos informes revisados (Castelleti y Vargas 1999; Contreras 2006; Borie 2007; Cabello 2008; Ajata 2013; Baeza 2013; Bahamondes y Correa 2013b; SGA 2013a, 2013b y 2013c; Duarte 2014; IAL 2014).

23 Cabe precisar que, en el caso de los informes de EIA, estos 
Un primer rasgo que llama la atención al estudiar la imagen generada por la clasificación supervisada es la importante concentración de sitios prehispánicos en los dos sectores principales definidos en función de los análisis realizados sobre las imágenes satelitales (interior de Pampa Yolanda Norte, al norte de la escena, y entorno de Pampa Altamira, al sur de la misma). Dado que éstos corresponden a terrenos donde se emplazan proyectos industriales, energéticos o de mejoramiento vial que han demandado el desarrollo de prospecciones arqueológicas sistemáticas en áreas acotadas (Contreras 2006; Borie 2007; Cabello 2008; Ajata 2013; SGA 2013a, 2013b y 2013c; Duarte 2014; IAL 2014), esta concentración de yacimientos y la escasez de registros de sitios de procesamiento lítico en otros sectores de la Depresión Intermedia debe ser considerada, por ahora, solo como una tendencia espacial sugerente.

Otro rasgo a destacar es la presencia predominante de sitios de trabajo lítico en terrenos definidos como depósitos aluviales o coluviales que se ubican en zonas de arrastre natural, asociadas a formaciones geológicas identificadas por los análisis de teledetección como portadoras de rocas silíceas y silicificadas. Como se señaló anteriormente, estas últimas formaciones se corresponderían con áreas dominadas por secuencias y complejos volcánicos continentales (SERNAGEOMIN 2003). Esta correspondencia entre áreas de concentración de sitios de procesamiento lítico y áreas de arrastre aluvial o coluvial se aprecia con claridad en el sector resaltado anteriormente en la mitad norte de la escena (Pampa Yolanda Norte y terrenos al interior de ella) (Figura 6). Allí los sitios arqueológicos se tienden a agrupar en el extremo sur de la extensa zona de arrastre de nódulos que se despliega hasta $13 \mathrm{~km}$ al sur del aforamiento/cantera de Pampa Yolanda Norte (cerro Punta Amarilla) y también, notablemente, en aquella que se desarrolla al norponiente de Sierra del Toro (SGA 2013a, 2013b y 2013c; IAL 2014), siendo de relativa menor densidad y potencia el conjunto de sitios de procesamiento lítico documentado al noreste de este mismo macizo y prácticamente nulo el registro

datos se obtuvieron a partir de los registros gráficos y/o escritos disponibles. Por lo tanto, son aproximativos y no representan el resultado de un estudio petrológico sistemático. El valor de $93 \%$ referido, considera como universo de análisis solo aquellos hallazgos para los que se contaba con información respecto a materias primas $(n=1112)$. arqueológico fuera de las áreas de interés resaltadas por la clasificación supervisada (IAL 2014). A ellas se suman otras áreas de arrastre al oeste y suroeste de Sierra del Toro, que podrían relacionarse con los contextos de aprovisionamiento lítico registrados a la altura de la Ruta 5 (Ajata 2013; SGA 2013a, 2013b y 2013c).

En el sector sur del área de estudio, el abanico aluvialcoluvial que se abre hacia el poniente de la quebrada $\mathrm{Ca}$ china, formando la Pampa Cachina, alberga nódulos de rocas silíceas o silicificadas de color predominantemente café grisáceo (Baeza 2013; Bahamondes y Correa 2013a), presumiblemente arrastrados a través de la quebrada $\mathrm{Ca}$ china desde el cerro Veraguas, ubicado a $20 \mathrm{~km}$ al oeste, o incluso desde el más distante cerro donde se registró el aforamiento/cantera de Pampa Altamira (Figura 7). Las prospecciones de obras lineales asociadas al proyecto minero Las Luces arrojaron un total de 160 eventos de talla en este abanico y no indicaron la presencia de sitios líticos en la proyección de las obras lineales al norte o al sur del mismo (Baeza 2013).

Un escenario distinto parece ser el documentado en el sector de Mina Franke, pues los sitios arqueológicos allí consignados (Contreras 2006) se emplazan en terrenos definidos como secuencias volcánicas (SERNAGEOMIN 2003) y no en áreas de arrastre aluvial/coluvial, aunque no es descartable en el sector la presencia en baja densidad de nódulos de materias primas silíceas y silicificadas movilizados por factores naturales desde el vecino cerro Veraguas y/o del cerro Guanaco. Esta última posibilidad sería coherente con un registro arqueológico representado mayoritariamente por eventos de talla aislados y concentraciones de eventos de talla espacialmente segregados, sin presencia de áreas de afloramiento/cantera (Contreras 2006).

Un último punto a abordar en esta discusión, tiene que ver con aquellos sitios de procesamiento lítico registrados durante reconocimientos de los proyectos FONDECYT 1110196 y 1151203 en las principales quebradas transversales que cruzan la Depresión Intermedia entre Taltal y Paposo, cuyas cabeceras se localizan a una distancia promedio de $40 \mathrm{~km}$ lineales de la costa actual. De norte a sur estos cursos de agua activados por lluvias torrenciales son: quebrada Matancilla ( $n$ de sitios $=7$ ), quebrada Bandurrias ( $n$ de sitios $=8)$, quebrada Cascabeles $(n$ de sitios = 26), y quebrada San Ramón ( $n$ de sitios $=1$ ) (Figura 9). 


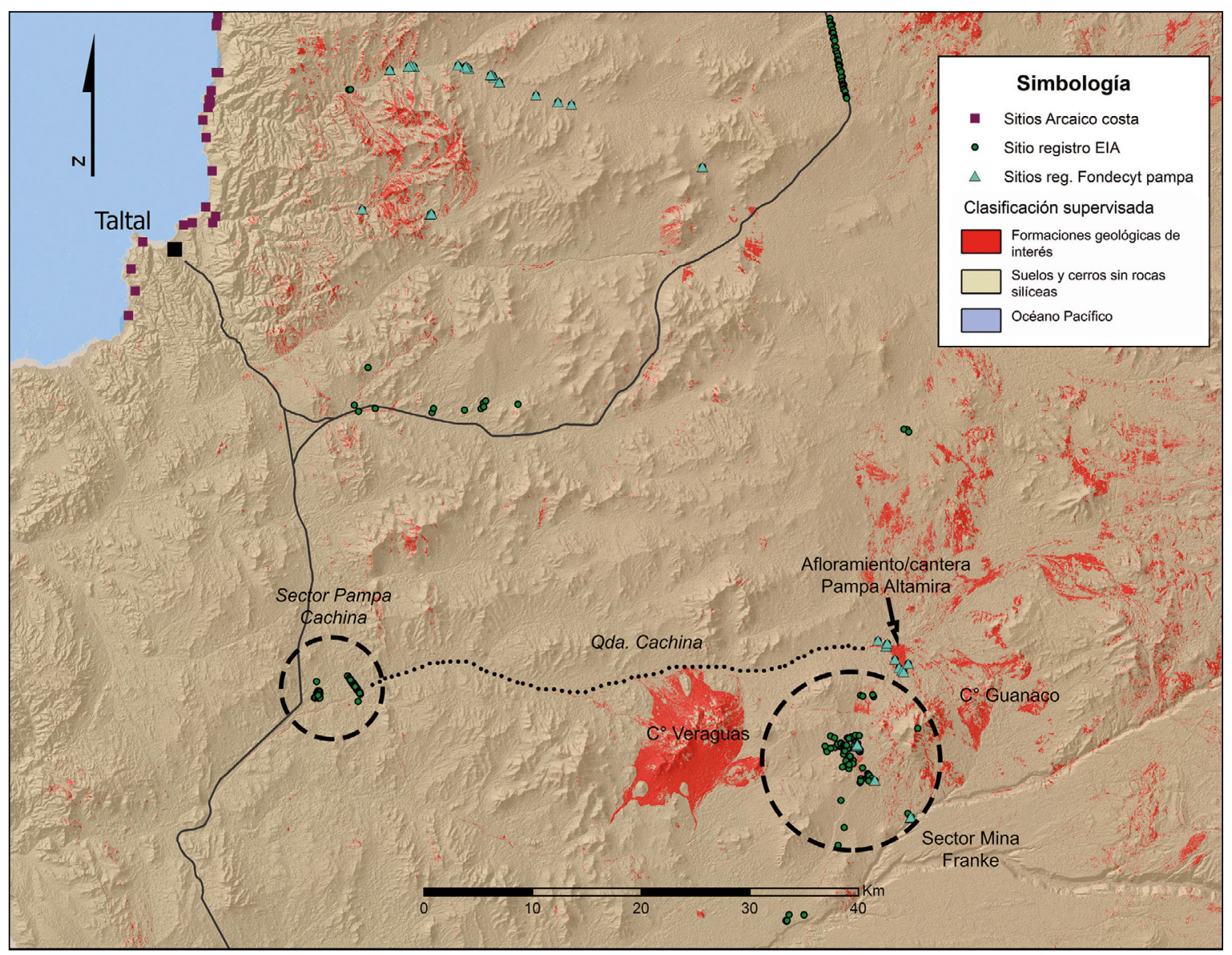

Figura 7. Detalle del segmento sur de la imagen clasificada Landsat 8 del área de estudio con el detalle de sus principales sectores y los sitios arqueológicos registrados.

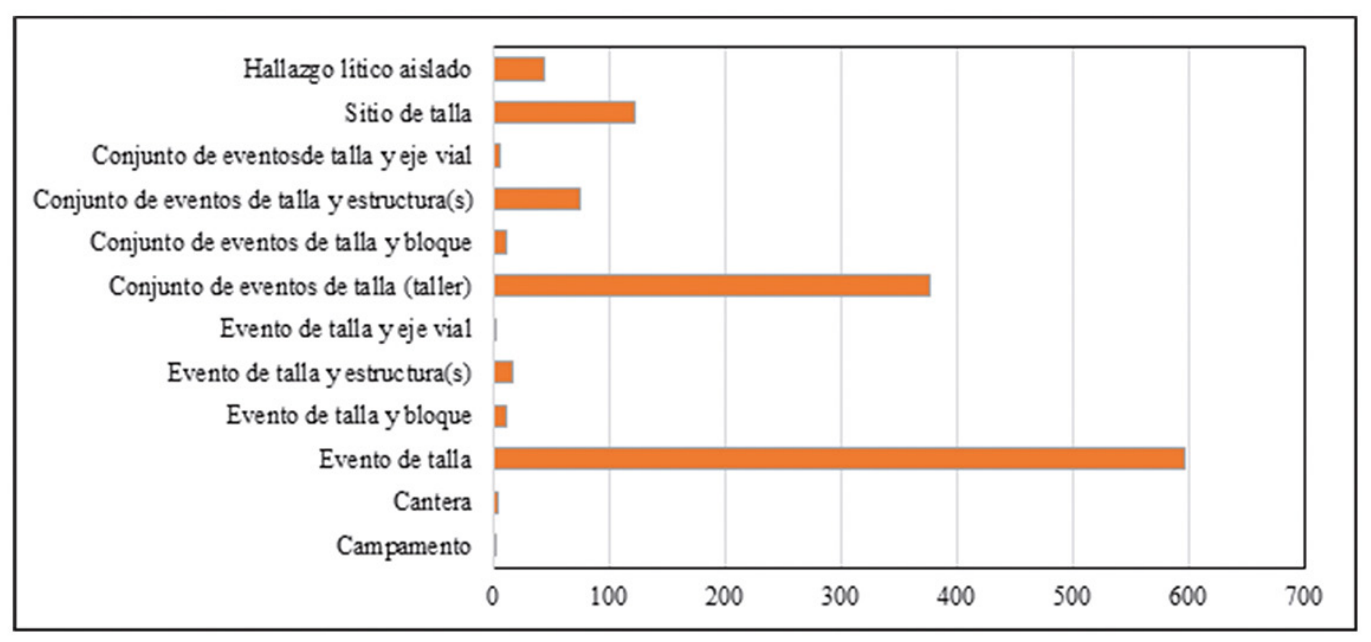

Figura 8. Cuantificación (expresada en valores absolutos) de los sitios arqueológicos con evidencias líticas en el área de estudio agrupados en categorías generales. 


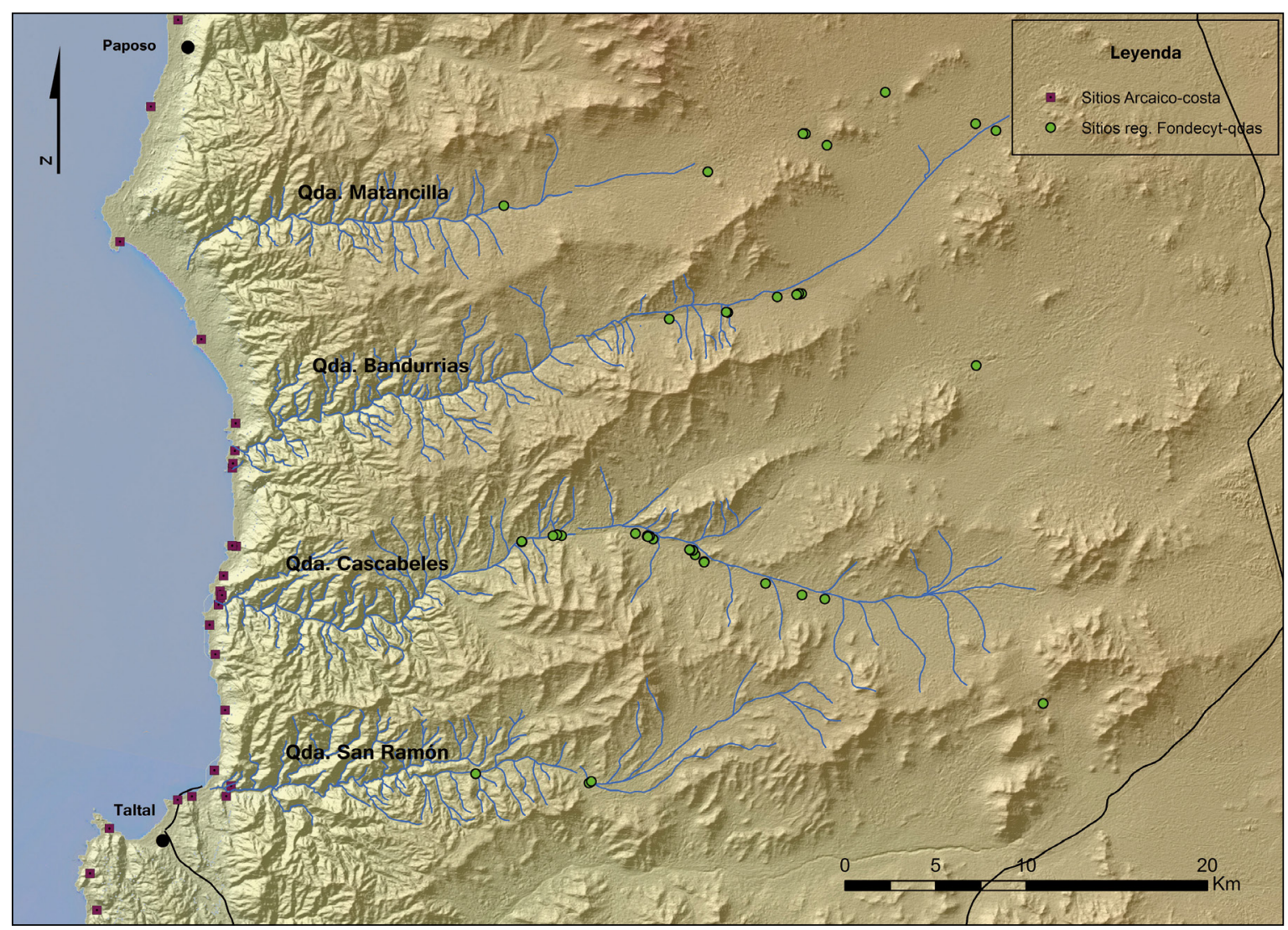

Figura 9. Mapa de las principales quebradas con acceso a la Depresión Intermedia entre Taltal y Paposo. En círculos verdes se indican los sitios con evidencias de procesamiento lítico registrados en ellas.

Si bien no se trata de registros realizados en el marco de prospecciones pedestres sistemáticas, lo cual puede introducir sesgos en las categorías de sitios identificados, ciertos rasgos de estos contextos ameritan mención, como la significativa presencia de conjuntos de eventos de talla asociados a estructuras subcirculares de piedra o a bloques erráticos ( 38 de los 42 sitios documentados a la fecha), un importante registro en superficie de evidencias correspondientes a fases intermedias y avanzadas del proceso de desbaste lítico de materias primas silíceas y silicificadas, además del hallazgo, en escasa frecuencia, de materialidades que dan cuenta de la realización en el lugar de otro tipo de actividades distintas a la talla lítica, como restos malacológicos de la costa Pacífico e instrumentos para la molienda de pigmento rojo (Figura 10). Estos rasgos contrastan con el panorama arqueológico de los terrenos de la Depresión Intermedia que se extienden más al este, donde los sitios con evidencias distintas a aquellas que remiten directamente al procesamiento lítico es prácticamente nulo y dominan en los conjuntos superficiales los desechos de fases primarias de este proceso, siendo recurrente en estos conjuntos el registro de matrices bifaciales.

Estos antecedentes permiten interpretar preliminarmente los sitios documentados en principales quebradas del sector norte del área de estudio, como contextos que funcionaron a manera de eslabones en dinámicas de movilidad prehispánicas trazadas entre la costa y las potentes áreas fuente líticas de la porción central de la Depresión Intermedia de Taltal, constituyendo nodos discretos en terrenos de desierto absoluto. La ausencia de restos cerámicos u otro tipo de evidencia que remita a estrategias de movilidad caravánica (Pimentel et al. 2011) haría posible su adscripción cronológica provisoria a períodos arcaicos. 


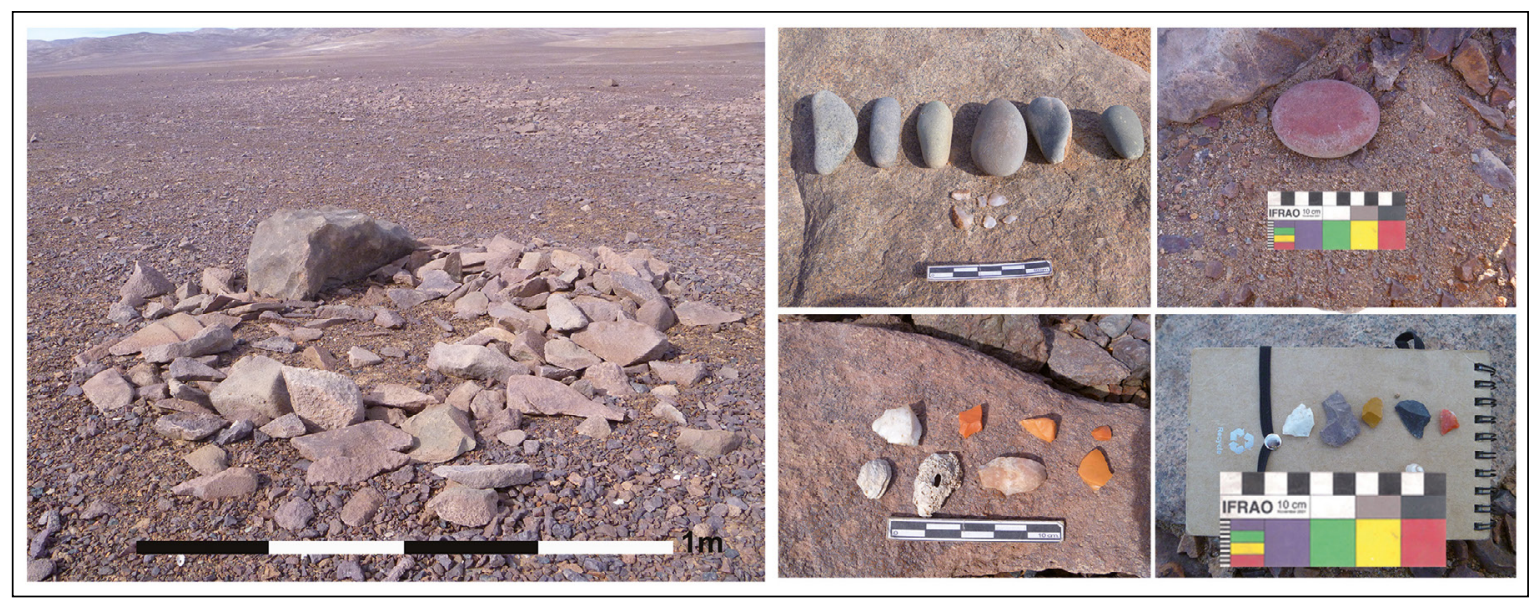

Figura 10. Vista general y detalle de materiales registrados en sitios de procesamiento lítico en el sector de quebrada Cascabeles.

Por otra parte, la abundancia de sitios con estructuras -o reparos junto a bloques erráticos aislados- y el hallazgo en ellos de conjuntos de percutores de cantos rodados marinos (en un caso con al menos seis ejemplares), daría cuenta de conductas de equipamiento de espacios para el pernocte, la reducción de matrices líticas de alta calidad, el consumo de alimentos y, probablemente, para la captación de recursos líticos y minerales disponibles en la serranías de su entorno.

Lo anterior implicaría que este tipo de sitios no fueron exclusivamente nodos de conexión en el movimiento hacia y desde las áreas fuente localizadas a mayor distancia al interior de la pampa, sino que pudieron actuar también - de manera sincrónica o no-como puntos terminales de desplazamientos de menor alcance, originados en la costa y dirigidos a la explotación de materias primas líticas y minerales ampliamente disponibles en el sector de las sierras costeras, como el cuarzo y los óxidos de hierro. A lo anterior se debe sumar su posible uso como cotos de caza, específicamente en el caso de aquellos sitios en el curso medio y bajo de las quebradas, emplazados en terrenos próximos a las aguadas de la estribación este de la cordillera de la Costa.

Futuros estudios estratigráficos en estos yacimientos y análisis de laboratorio de los materiales recuperados en ellos, aportarán nuevos datos que permitan afirmar o refutar esta interpretación.

\section{$\because$ Comentarios finales}

Los resultados presentados, pese a que constituyen solo una exploración preliminar de algunas de las técnicas contempladas en la propuesta metodológica aquí desarrollada, son alentadores en cuanto a la potencialidad de las estrategias de teledetección satelital para la identificación remota de formaciones geológicas portadoras de rocas silíceas y silicificadas en el área de Taltal. Una capacidad que podría ser explotada para acotar, de manera efectiva e informada, las áreas de búsqueda para la realización de campañas de prospección sistemática en contextos de estudio afines.

A su vez, los datos generados en este primer acercamiento, posibilitan y extienden la discusión de la problemática de los patrones de asentamiento/movilidad de las poblaciones arcaicas costeras, de manera consistente al registro arqueológico de la Depresión Intermedia de Taltal. Fundamentalmente, desde una perspectiva multidisciplinaria e integradora, se aportan nuevos antecedentes e interpretaciones orientados a la reconstrucción del paisaje lítico en el que ellas se desenvolvieron.

En etapas más avanzadas de la investigación, los resultados de los análisis de espectroscopía de reflectividad sobre muestras líticas de los distintos contextos en estudio, serán una pieza clave para la adecuada caracterización de las áreas fuente líticas explotadas por las poblacio- 
nes arcaicas costeras de Taltal, tarea imprescindible en el desarrollo de estudios de procedencia de sílices, una materialidad de reconocida importancia dentro de su organización tecnológica.

Los estudios espectroscópicos de laboratorio, al proporcionar firmas espectrales detalladas de los materiales líticos silíceos y silicificados prioritariamente utilizados a lo largo de la secuencia arcaica de Taltal, facilitarán la búsqueda en las imágenes satelitales multiespectrales de aquellas formaciones geológicas a las que los grupos cazadores-recolectores-pescadores locales accedieron recurrentemente en busca de materias primas de alta calidad para la talla, y permitirán indagar en la explotación diferencial de fuentes líticas específicas en los distintos períodos que conforman esta secuencia prehispánica. De esta forma, se abrirá el camino a una reconstrucción más fina del paisaje lítico local y a la realización de análisis que exploren, mediante modelamientos digitales, la estructuración del mismo a raíz de las dinámicas de movilidad generadas entre la costa y las distintas áreas fuente localizadas en la Depresión Intermedia.

A través de prospecciones pedestres de carácter dirigido y sistemático, los resultados obtenidos a partir de análisis de teledetección satelital y modelamientos de movilidad serán evaluados en terreno en cuanto a su capacidad para relevar tendencias en la organización espacial del registro arqueológico del área de estudio. Estas tendencias posteriormente podrán ser exploradas con mayor detalle al definir subzonas de interés específico (p.e. un corredor de movilidad entre la costa y un área fuente determina$\mathrm{da}$, con sus distintas locaciones de procesamiento lítico asociadas). Lo anterior al incorporar en el análisis de estas subzonas el uso de imágenes satelitales superiores a las Landsat 8 en términos de su resolución espectral y/o de escenas con una mayor resolución espectral y espacial (Parcak 2009).

A lo largo de estas líneas, se buscó ser enfático en el carácter preliminar de los resultados obtenidos, puesto que es necesario complementar y refinar toda estrategia de detección satelital de áreas fuente líticas mediante análisis de laboratorio y trabajos de campo arqueológicos y geológicos. Solo a partir de estudios dirigidos al registro en terreno y caracterización de estas áreas fuente, será posible representar de manera adecuada la variabilidad contenida en las distintas materias primas silíceas y silicificadas diferencialmente distribuidas en los vastos territorios y a lo largo de la extensa secuencia cronológica abarcados por los contextos arqueológicos arcaicos de la costa desértica de Chile. Éste se considera un paso fundamental para el avance crítico y a paso firme en la línea de investigación aquí inaugurada.

Agradecimientos Este trabajo ha sido financiado por el Proyecto FONDECYT 1151203. Corresponde agradecer a quienes han colaborado a la reflexión y discusión de la problemática aquí presentada como parte del equipo de trabajo y laboratorio del proyecto, también a Pastor Fábrega-Álvarez, Antonio Uriarte y Ryan Parish por sus asesorías remotas en temas de teledetección y espectroscopía, y a José Castelleti y Gloria Cabello por facilitar el acceso a los trabajos arqueológicos de Carlos Urrejola y Mario Orellana en el área de estudio. 


\section{$*$ Referencias citadas}

AJATA, R. 2013. Línea de base arqueológica y del patrimonio cultural, estudio de ingeniería reposición Ruta 5 tramo sector Yumbe-Los Vientos, Región de Antofagasta. Dolmen Ingeniería Sustentable. Ms. en posesión del autor.

AMER, R., T. KUSKY, P. REINERT y A. GHULAM. 2009. Image processing and analysis using Landsat ETM+ imagery for lithological mapping at Fawakhir, central eastern desert of Egypt. The American Society for Photogrammetry and Remote Sensing Annual Conference Proceedings, Baltimore.

ANDRADE, Py D. SALAZAR. 2011. Revisitando Morro Colorado: comparaciones y propuestas preliminares en torno a un conchal arcaico en las costas de Taltal. Taltalia 4: 63-83.

ANDRADE, P., R. FERNANDES, K. CODJAMBASSIS, J. URREA, L. OlGUÍN, S. REBOLLEDO, F. LIRA, C. ARAVENA y M. BERRÍOS. 2015. Subsistence Continuity Linked to Consumption of Marine Protein in the Formative Period in the Interfluvic Coast of Northern Chile: Re-Assessing Contacts with Agropastoral Groups from Highlands. Radiocarbon 57: 679-688.

ANDREFSKY, W. 1994. Raw-material availability and the organization of technology. American Antiquity 59(1): 21-34.

ANDREFSKY, W. 2008. The Analysis of Stone Tool Procurement, Production, and Maintenance. Journal of Archaeological Research 17(1): 65-103.

BAEZA, V. 2013. Informe de Prospección Superficial Arqueológica, Proyecto actualización y modificación Proyecto Las Luces, Taltal, Región de Antofagasta. Ms.

BAHAMONDES, F. e I. CORREA. 2013a. Línea de base arqueológica Proyecto Planta Solar Fotovoltaica Pampa Sur Comuna de Taltal, II Región de Antofagasta. Informe preparado por Ingenostrum. Ms.

BAHAMONDES, F. 2013b. Línea de base arqueológica Proyecto Planta Solar Fotovoltaica Pampa Solar Norte Comuna de Taltal, II Región de Antofagasta. Informe preparado por Ingenostrum. Ms.

BALLESTER, B. y F. GALLARDO. 2011. Prehistoric and historic networks on the Atacama Desert coast (northern Chile). Antiquity $85: 875-889$.

BAMFORTH, D. 1986. Technological efficiency and tool curation. American Antiquity 51(1):38-50.

BERDICHEWSKY, B. 1962. El Precerámico de Taltaly sus correlaciones. Centro de Estudios Antropológicos, Universidad de Chile. Publicación núm. 16. Santiago.
BINFORD, L. 1979. Organization and formation processes: looking at curated technologies. Journal of Anthropological Research 35(3): 255-73.

BINFORD, L. 1980. Willow smoke and dogs' tails: hunter-gatherer settlement systems and archaeological site formation. American Antiquity 45(1): 4-20.

BIRD, J. 1943. Excavations in Northern Chile. Anthropological Papers of the American Museum of Natural History 38: 178-318.

BIRD, J. 1965. The concept of a "pre-projectile point" cultural stage in Chile and Perú. American Antiquity 31: 262-270.

BITTMANN, B. 1977. Notas sobre poblaciones de la costa del norte Grande Chileno. En Aproximación a la Etnohistoria del Norte y Tierras adyacentes, J. Casassas (Ed.).

BITTMANN, B. y J. MUNIZAGA. 1984. Evolución en poblaciones precolombinas de la costa Norte de Chile. Chungara 13: 129-142.

BLANCO, J., M. DE LA MAZA y CH. REES. 2010. Cazadores recolectores costeros y el aprovisionamiento de recursos líticos. Perspectivas interpretativas de los eventos de talla en el desierto absoluto. Werkén 13: 45-68.

BORIE, C. 2007. Inventario recursos culturales, Inspección visual componente arqueológico Proyecto "Explotación de Minas Minera Las Cenizas S.A.”. Informe preparado por MAA Consultores para MYMA LTDA. Ms.

BORIE, C. y C. SOTO. 2011. Prospecciones arqueológicas en la costa norte de Taltal. Taltalia 4: 85-101.

BROWNE, C. y L. WILSON. 2013. Evaluating inputs to models of hominin raw material selection: Map resolution and path choices. Journal of Archaeological Science 40(11): 3955-3962.

CABELLO, G. 2008. Aspectos culturales y arqueológicos Proyecto reapertura mina Guanaco, II Región, Antofagasta, Declaración de impacto ambiental Proyecto reapertura mina Guanaco, Anexo G. Informe preparado para Guanaco Compañía Minera. Ms.

CAPDEVILLE, A. 1921. Notas acerca de la arqueología de Taltal. Boletín Nacional de la Historia 3, 4, 5, 7, 8. Quito.

CARR, T. y M. TURNER. 1996. Investigating regional lithic procurement using multi-gspectral imagery and geophysical exploration. Archaeological Prospection 3: 109-127. 
CASTELLETI, J. 2007. Patrón de Asentamiento y uso de recursos a través de la secuencia ocupacional prehispana en la costa de Taltal. Memoria para optar al grado de Magíster en Antropología con mención en Arqueología. Convenio Universidad Católica del Norte - Universidad de Tarapacá. Antofagasta.

CASTELLETI, J. y M. VARGAS. 1999. Informe final Actividades realizadas en el monitoreo arqueológico Línea Paposo-Diego de Almagro. Informe preparado para TRANSELEC. Ms.

CASTElLETI, J., O. REYES, G. MALTRAIN, I. MARTÍNEZ, P. GALARCE, H. VELÁSQUEZ y J. OGALDE. 2010. Ocupaciones en abrigos rocosos en la costa de Taltal: patrón de uso del espacio desde momentos Holocénicos Tempranos. En Actas del XVII Congreso Nacional de Arqueología Chilena, L. Adán (Ed.), vol. 2, pp. 685-695, Ediciones Kultrún, Valdivia.

CHATTERS, J. 1987. Hunter-gatherer adaptations and assemblage structure. Journal of Anthropological Archaeology 6(4): 336-375.

CHÁVEZ, P., S. SIDES y J. ANDERSON. 1991. Comparison of three different methods to merge multiresolution and multispectral data: Landsat TM and SPOT panchromatic, Photogrammetric Engineering \& Remote Sensing 57(3): 295-303.

CHUVIECO, E. 2006. Teledetección Ambiental, segunda edición. Editorial Ariel, Barcelona.

CLARK, R. 1999. Spectroscopy of rocks and minerals, and principles of spectroscopy. En Manual of Remote Sensing, A. Rencz (Ed.), John Wiley and Sons, Inc. Nueva York.

CONROY, G., C. EMERSON, R. ANEMONE y B. TOWNSEND. 2012. Let your fingers do the walking: A simple spectral signature model for "remote" fossil prospecting. Journal of Human Evolution 63: 79-84.

CONTRERAS, L. 2006. Patrimonio histórico-arqueológico, Proyecto Franke. Informe preparado por Arcadis Geotécnica. Ms.

CONTRERAS, R., P. NÚÑEZ, A. LlagOSTERA, J. CRUZ, A. SAN FRANCISCO, B. BALLESTER, O. RODRÍGUEZ y G. BECERRA. 2011. Un conglomerado del período Arcaico Costero Medio del área Taltal Paposo, norte de Chile. Taltalia 4: 7-31.

CRANDELL, O. 2006. Macroscopic and microscopic analysis of chert. A proposal for standardization of methodology and terminology. Buletinul Cercurilor Stiintifice Studentesti 12: 7-30.

DUARTE, A. 2014. Informe de Línea de Base Arqueológica Proyecto "Explotación Mina Amancaya". Informe preparado para Guanaco, Compañía Minera. Ms.
DUKE, C. y J. STEELE. 2010. Geology and lithic procurement in Upper Palaeolithic Europe: a weights-of-evidence based GIS model of lithic resource potential. Journal of Archaeological Science 37: $813-824$.

DUNAI, T., G. GONZÁLEZ y J. JUEZ-LARRÉ. 2005. OligoceneMiocene age aridity in the Atacama Desert revealed by exposure dating of erosion-sensitive landforms. Geology 33(4): 321, 324.

DURÁN, A. 1981. Investigación arqueológica en Punta Grande. Memoria para optar al título de Arqueólogo. Universidad del Norte, Antofagasta, Chile.

FÁBREGA-ÁLVAREZ, P. 2006. Moving without destination: a theoretical, GIS based determination of routes (optimal accumulation model of movement from a given origin). Archaeological Computing Newsletter 64: 7-12.

FÁBREGA-ÁLVAREZ, P., J. FONTE y F. GONZÁLEZ. 2011. Mobilidade e materialidade: uma aproximação à análise da localização das estátuas-menir transfronteiriças (Norte de Portugal e Sul da Galiza). En Estelas e Estátuas-menires: Da Pré à Proto-história, R. Vilaça (Ed.), pp. 245-270. Actas Das IV Jornadas Raianas 2009, CEAUCP/Sabugal, Sabugal, Portugal.

GALARCE, P. y G. SANTANDER. 2013. Contextos líticos de asentamientos arcaicos en la costa de Taltal (II Región, Chile). Estudios Atacameños 46: 5-26.

GALARCE, P. 2014. Bifacialidad, circulación de materias primas y movilidad de comunidades cazadoras recolectoras holocénicas en el semiárido meridional. Tesis para obtener el grado de Magíster en Antropología con mención en Arqueología. Universidad de Tarapacá y Centro de Investigaciones del Hombre en el Desierto, Arica.

GAETE, N., X. NAVARRO y M. VARGAS. 2003. Plan de Rescate Arqueológico Ruta 1 Sector Taltal-Punta Viento, sitios "Morro Colorado, Punta Morada y Pozo Bahamondes". Convenio MOPCMT. Consejo de Monumentos Nacionales. Ms.

GOODYEAR, A. 1979. A hypothesis for the use of cryptocrystalline raw materials among Paleoindian groups of North America. Research Manuscript Series 1 (156). Columbia, SC: Institute of Archeology and Anthropology, University of South Carolina.

GOULD, R y S. SAGGERS. 1985. Lithic procurement in Central Australia: a closer look at Binford's idea of embeddedness in archaeology. American Antiquity 50(1): 117-136.

GREISER, S. y P. SHEETS. 1979. Raw Materials as a Functional Variable in Use-Wear Studies. En Lithic Use-WearAnalysis, B. Hayden (Ed.), pp. 289-296. Academic Press, New York. 
GUENDON, J. 2008. Informe Geomorfológico Proyecto FONDECYT 1080666. Ms.

HERRERA, C.y E. CUSTODIO. 2014. Origin of waters from small springs located at the northern coast of Chile, in the vicinity of Antofagasta. Andean Geology 41(2): 314-341.

HOUSTON, J. 2006. Variability of precipitation in the Atacama Desert: its causes and hydrological impact. International Journal of Climatology 26: 2181-2198.

HUBBARD, M., D. WAUGH y J. ORTIZ. 2005. Provenance determination of archaeological cherts by VIS/NIR diffuse reflectance spectrometry. The Compass 78: 119-129.

IAL AMBIENTAL. 2014. Declaración de impacto ambiental Prospección Minera Arbiodo. Anexo 4. Informe preparado para Ingenieros Asesores Ltda. Ms.

IGM. 1990. Geografía II Región de Antofagasta. Colección Geografía de Chile. Santiago de Chile. Instituto Geográfico Militar.

KELLY, R. 1988. Three sides of a biface. American Antiquity 53: 717734 .

KELLY, R. 2012. Obsidian in the Carson Desert: mobility or trade? En Perspectives on Prehistoric Trade and Exchange in California and the Great Basin, R. Hughes (Ed.). University of Utah Press.

LE PAIGE, G. 1964. El precerámico en la cordillera de Atacama y los cementerios del período agroalfarero de San Pedro de Atacama. Anales de la Universidad del Norte 3.

LE PAIGE, G. 1971. Ponencia en el VI Congreso de Arqueología Chilena, 1971.

LEVERINGTON, D. y W. MOON. 2012. Landsat-TM-based discrimination of lithological units associated with the Purtuniq ophiolite, Quebec, Canada. Remote Sensing 4: 1208-1231.

LLAGOSTERA, A. y V. LLAGOSTERA. 2010. Enterratorios del sitio arqueológicos Los Bronces-1, Comuna de Taltal (Región de Antofagasta). Taltalia 3: 7-20.

LLOBERA, M., P. FÁBREGA-ÁLVAREZ y C. PARCERO-OUBINA. 2011. Order in movement: a GIS approach to accessibility. Journal of Archaeological Science 38(4): 843-851.

LP DAAC. Land Processes Distributed Active Center. https://lpdaac.usgs.gov/dataset_discovery/aster/aster_products_table/ $\operatorname{astgtm}(16.12 .2013)$.
LUEDTKE, B. 1979. The identification of source chert artifacts. American antiquity 44 (4): 744-757.

MARQUET, P., F. BOZINOVIC, G. BRADSHAW, C. CORNELIUS, H. GONZÁLEZ, J. GUTIÉRREZ, E. HAJEK, J. LAGOS, F. LÓPEZ-CORTÉS, L. NÚÑEZ, E. ROSELLO, C. SANTORO, H. SAMANIEGO, V. STANDEN, J. TORRES-MURA y F. JAKSIC. 1998. Los ecosistemas del desierto de Atacama y área andina adyacente en el norte de Chile. Revista Chilena de Historia Natural 71: 593-617.

MAYORAL, V., E. CERRILLO CUENCA y S. CELESTINO PÉREZ. 2009. Métodos de prospección arqueológica intensiva en el marco de un proyecto regional: el caso de la comarca de $\mathrm{La}$ Serena (Badajoz). Trabajos de Prehistoria 66(1): 7-26.

MCCALL, G. 2012. Ethnoarchaeology and the organization of lithic technology. Journal of Archaeological Research 20(2): 157-203.

MELTZER, D. 1989. Was Stone Exchanged among Eastern North American Paleoindians? En Eastern Paleoindian Lithic Resource Use, C. Ellis y J. Lothrop (Eds.), pp. 11-39. Westview Press, Boulder.

MENA, F. 1984. Patrones de movilidad en el Arcaico Tardío: II Región. Estudios Atacameños 7: 25-35.

NELSON, M. 1991. The study of technological organization. En Archaeological Method and Theory, M Schiffer (Ed.), pp. 57-100. University of Arizona Press, Tucson, AZ.

NÚÑEZ. L. 1984. Secuencia de asentamientos prehistóricos del área de Taltal. En Tres ensayos para una historia de Taltal y su zona. Futuro 8: 28-76.

NÚÑEZ, L. y J. VARELA. 1967-1968. Sobre los recursos de agua y el poblamiento prehispánico de la Costa del Norte Grande de Chile. Estudios arqueológicos 3-4: 7-41.

OLGUÍN, L., D. SALAZAR y D. JACKSON. 2014. Tempranas evidencias de navegación y caza de especies oceánicas en la costa pacífica de Sudamérica (Taltal, 7.000 años cal. AP). Chungara 46: 177-192.

ORTLIEB, L., G. VARGAS y J. SALIÉGE. 2011. Marine radiocarbon reservoir effect along the northern Chile-southern Peru coast $\left(14-24^{\circ} \mathrm{S}\right)$ throughout the Holocene. Quaternary Research 75: 91-103.

PARCAK, S. 2009. Satellite Remote Sensing for Archaeology. Routledge, Nueva York. 
PARCERO-OUBIÑA, C. y FÁBREGA-ÁLVAREZ, P. 2006. Diseño metodológico para el análisis locacional de asentamientos a través de un SIG de base raster. En La Aplicación de Los SIG en La Arqueología del Paisaje, I. Grau Mira (Ed.), pp. 69-91. Universidad de Alicante, España.

PARISH, R. 2011. The application of visible/near-infrared reflectance (VNIR) spectroscopy to chert: a case study from the Dover quarry sites, Tennessee. Geoarchaeology: An International Journal $26(3): 420-439$.

PARISH, R., G. HAMMOND y L. YING. 2013. Evaluating fourier transform infrared spectroscopy as a non-destructive chert sourcing technique. Geoarchaeology: An International Journal 28 (3): 289-307

PERALTA, P., C. GONZÁLEZ, C. WESTFALLy G. SANTANDER. 2010. Primeras aproximaciones sobre la arqueología de Pampa Austral: explotación y tecnología lítica al interior de la Región de Atacama (Chile). Actas del XVII Congreso Nacional de Arqueología Chilena, L. Adán (Ed.), vol. 1, pp. 297-306. Ediciones Kultrún, Valdivia.

PIGNIOLO, A. 2009. Patterns in stone: Mobility and the distribution of locally important lithic material. SCA Proceedings 22: 1-10.

PIMENTEL, G., C. REES, P. DE SOUZA y L. ARANCIBIA. 2011. Viajeros costeros y caravaneros. Dos estrategias de movilidad en el Período Formativo del desierto de Atacama, Chile. En En Ruta. Arqueología, Historia y Etnografía del tráfico Sur Andino, L. Núñez y A. Nielsen (Eds.), pp. 43-81, Encuentro Grupo Editor, Córdova, Argentina.

PLACZEK C., A. MATMON, D. GRANGER, J. QUADE y S. NIEDERMANN. 2010. Evidence for active landscape evolution in the hyperarid Atacama from multiple terrestrial cosmogenic nuclides. Earth and Planetary Science Letters 295: 12-20.

PLISCOFF, P. y F. LUEBERT. 2008. Los Ecosistemas Terrestres. En Biodiversidad de Chile: Patrimonio y Desafio, J. Rovira, J. Ugalde y M. Stutzin (Eds.), pp. 74-87. Ocho Libros Editores, Santiago.

POWER, X. 2015. Función y estructura del sitio Caleta Bandurrias (Taltal, II Región de Antofagasta). Una evaluación sobre las poblaciones costeras de los "círculos de piedra". Tesis de grado para optar al título de Arqueólogo. Facultad de Ciencias Sociales, Universidad de Chile, Santiago.

QUEZADA, J., J. L. CERDA y A. JENSEN. 2010. Efectos de la tectónica y el clima en la configuración morfológica del relieve costero del norte de Chile. Andean Geology 37(1): 78-109.
REBOLledo, S. 2014. Arcaico Medio en la Costa Arreica: Estrategias de Caza y Pesca Costero marítima en el sitio Zapatero. Memoria para optar al título de Arqueóloga. Facultad de Ciencias Sociales, Universidad de Chile, Santiago.

ROSENDAHL, S. 2010. Lithic procurement strategies in early prehistoric Cyprus: A predictive model. Tesis para optar al grado de Master en Ciencias, Departamento de Geografía, Universidad de Leicester, Reino Unido.

SALAZAR, D., P. ANDRADE, C. BORIE, M. ESCOBAR, V. FIGUEROA, C. FLORES, L. OLGUÍN y H. SALINAS. 2013. Nuevos sitios correspondientes al Complejo Cultural Huentelauquén en la costa de Taltal. Taltalia 6: 9-19.

SALAZAR, D., V. FIGUEROA, P. ANDRADE, H. SALINAS, L. OLGUÍN, X. POWER, S. REBOLLEDO, S. PARRA, H. ORELLANA, y J. URREA. 2015. Cronología y organización económica de las poblaciones arcaicas de la costa de Taltal. Estudios Atacameños 50: 7-46.

SALINAS, H., A. CIFUENTES, S. PARRA y X. POWER. 2014. Informe material lítico. Sitios 225, 224-A, Morro Colorado y Zapatero. Taltal, II Región de Antofagasta. Anexo IV, Informe de Avance Año 3, Proyecto FONDECYT 1110196. Ms.

SERNAGEOMIN. 2003. Publicación Geológica Digital, núm. 4. Base geológica escala 1:1.000.000. Servicio Nacional de Geología y Minería, Chile.

SGA SOLUCIONES EN GESTIÓN AMBIENTAL. 2013a. Línea de Base Proyecto Solar Conejo. Prospección Arqueológica. Anexo núm. 6.1. Ms.

SGA SOLUCIONES EN GESTIÓN AMBIENTAL. 2013b. Declaración de Impacto Ambiental Proyecto Solar Toro. Prospección arqueológica. Anexo núm. 7. Ms.

SGA SOLUCIONES EN GESTIÓN AMBIENTAL. 2013c. Informe de Arqueología Modificación Proyecto Parque Eólico Taltal. Informe preparado para Parque Eólico Taltal S.A. Ms.

SHACKLEY, M. 2008. Archaeological petrology and the archaeometry of lithic materials. Archaeometry 50(2): 194-215.

SILVA, J. y D. BAHAMONDES. 1969. Investigaciones arqueológicas en Taltal, informe preliminar. En Actas del IV Congreso Nacional de Arqueología 2: 7-25. Rehue Ediciones.

SULTAN, M., R. ARVIDSON, N. STURCHIO y E. GUINNESS. 1987. Lithological mapping in arid regions with Landsat thematic mapper data: Meatiq dome, Egypt. Geological Society American Bulletin 99: 748-762. 
UHLE, M. 1916. Sobre la estación paleolítica de Taltal. Una carta y un informe. Revista Chilena de Historia y Geografía 24: 47-66.

URREJOLA, C. y M. ORELLANA. 200o. Explotación de recursos líticos en la zona desértica al interior de Taltal. En Actas del XV Congreso Nacional de Arqueología Chilena, Sección Comunicaciones, Arica, Chile.

USGS. U.S. Geological Survey. http://landsat.usgs.gov/landsat8. php (25.09. 2014).

VAN NIEL, T., T. MCVICAR y B. DATT. 2005. On the relationship between training sample size and data dimensionality: Monte Carlo analysis of broadband multi-temporal classification. Remote Sensing of Environment 98: 468-480.
VARELA, V. 2009. La cerámica arqueológica de Taltal. Taltalia 2: $119-128$.

VARGAS, G., J. RUTLLANT y L. ORTLIEB. 2006. ENSO tropicalextratropical climate teleconnections and mechanisms for Holocene debris flows along the hyperarid coast of western South America $\left(17^{\circ}-24^{\circ} \mathrm{S}\right)$. Earth and Planetary Science Letters 249: 467483.

WILSON, L. 2007. Understanding prehistoric lithic raw material selection: application of a gravity model. Journal of Archaeological Method and Theory 14(4): 388-411. 
